\title{
Topical treatment with a transient receptor potential ankyrin 1 (TRPA1) antagonist reduced nociception and inflammation in a thermal lesion model in rats
}

\author{
Caren Tatiane de David Antoniazzi ${ }^{\mathrm{a}}$, Samira Dal-Toé De Prá ${ }^{\mathrm{b}}$, Paula Ronsani Ferro ${ }^{\mathrm{b}}$, \\ Mariane Arnoldi Silva $^{c}$, Gabriela Adamante ${ }^{\mathrm{b}}$, Amanda Spring de Almeida ${ }^{\mathrm{a}}$, \\ Camila Camponogara ${ }^{\mathrm{d}}$, Cássia Regina da Silva ${ }^{\mathrm{e}}$, Gustavo de Bem Silveira ${ }^{\mathrm{b}}$, \\ Paulo Cesar Lock Silveira ${ }^{\mathrm{b}}$, Sara Marchesan Oliveira ${ }^{\mathrm{d}}$, Flávia Karine Rigo ${ }^{\mathrm{b}}$, Francesco De Logu ${ }^{\mathrm{f}}$, \\ Romina Nassini ${ }^{\mathrm{f}}$, Gabriela Trevisan ${ }^{\mathrm{a}, \mathrm{b}, *}$ \\ a Graduated Program in Pharmacology, Federal University of Santa Maria (UFSM), 97105-900 Santa Maria, RS, Brazil \\ ${ }^{\mathrm{b}}$ Graduated Program in Health Sciences, University of the Extreme South of Santa Catarina (Unesc), 88006-000 Criciúma, SC, Brazil \\ c Faculty META (META), 69914-220 Rio Branco, AC, Brazil \\ d Graduated Program in Biological Sciences: Toxicological Biochemistry, Federal University of Santa Maria (UFSM), 97105-900 Santa Maria, RS, Brazil \\ e Genetics and Biochemistry Institute, Federal University of Uberlândia, 38408-100 Uberlândia, MG, Brazil \\ ${ }^{\mathrm{f}}$ Department of Health Sciences, Section of Clinical Pharmacology and Oncology, University of Florence, Florence 50139, Italy
}

\section{A R T I C L E I N F O}

\section{Keywords:}

HC-030031

Burn

Allodynia

Anti-inflammatory

Hydrogen peroxide, NADPH oxidase

\begin{abstract}
A B S T R A C T
Thermal injury promotes tissue inflammation and pain, which is difficult to control. Different peripheral mechanisms seem to be involved in burn pain, such as free radical-induced damage, but further study is still needed to understand how oxidant substances induced nociceptor sensitization. The transient receptor potential ankyrin 1 (TRPA1) is an ion channel activated by oxidants substances, and it could be sensitized after tissue inflammation. This study evaluated the TRPA1 involvement in nociception and inflammation produced by a thermal injury model. Male Wistar rats were used. The concentration of the TRPA1 antagonist (HC-030031, $0.05 \%$ ) on base cream was chosen using allyl isothiocyanate intraplantar test. Then, the base cream containing HC-030031 was tested on the thermal injury model (induced by warm water immersion of hind paw, under anesthesia), and silver sulfadiazine ( $1 \%$ ) was used as a positive control. Cream treatments on the hind paw were done daily ( $200 \mathrm{mg} /$ paw) for 6 days after thermal injury. Also, nociception (static and dynamic mechanical allodynia, heat allodynia, and spontaneous pain) or edema were evaluated. On day 6, inflammatory and oxidative parameters were assessed. The base cream containing HC-030031 produced antinociceptive and antiinflammatory effects (reduced the edema and inflammatory cells infiltration) and decreased the levels of hydrogen peroxide, or superoxide dismutase and NADPH oxidase activities after thermal injury. Thus, this study showed the involvement of the TRPA1 receptor in the nociception and inflammation caused by thermal injury and suggested that TRPA1 antagonists might be useful as novel treatments for pain and inflammation by topical application.
\end{abstract}

\section{Introduction}

Burns are lesions damaging organic tissues, usually caused by exposure to external agents such as solar radiation, contact with hot surfaces and flames, or even contact with liquids at high temperature (Bishop et al., 2007; Evers et al., 2010; Treede et al., 2015). Moreover, the type of burn, according to the depth and extent of the lesion, are factors that will directly influence the prognosis of the thermal injury and the form of pain which will be observed (McIntyre et al., 2016). Considering this, burns induced by liquids at high temperatures are usually first-degree lesions. In such cases, the primary symptoms observed are edema and pain, with intense inflammation and possible skin

\footnotetext{
* Corresponding author at: Graduated Program in Pharmacology, Federal University of Santa Maria (UFSM), Avenida Roraima, 1000, building 21, room 5207, 97105-900 Santa Maria, RS, Brazil.

E-mail address: gabriela.trevisan@ufsm.br (G. Trevisan).
} 
desquamation ( 3 to 7 days after the induction of the lesion) (Monstrey et al., 2008; Piccolo et al., 2008; Serrano et al., 2015).

Pain is one of the most incapacitating symptoms and represents a challenge after burn injury, due to the control difficulty, considering the currently available drugs in the clinic (Cuttle et al., 2009; McGaraughty et al., 2010; Richardson and Mustard, 2009). In patients with burns, the injury treatment during and after wound healing is still far from ideal, especially for pain control (Cuttle et al., 2009; Richardson and Mustard, 2009). In the case of first-degree burns, acute pain is accompanied by edema and redness of the affected area and is usually treated with the use of analgesics (ibuprofen, naproxen or even paracetamol) by oral administration (Walls et al., 2017). However, these medicines still did not induce complete relieve of inflammatory pain observed after burn injury (James and Jowza, 2017), in this sense it is interesting to investigate other mechanisms that could be involved in this type of pain (McIntyre et al., 2016).

One of the mechanisms involved in the inflammatory response and exacerbated edema observed in thermal lesions is the augmented production of reactive oxygen species (i.e., hydrogen peroxide), due to the activation of enzymes NADPH oxidase and superoxide dismutase (SOD) in inflammatory cells, such as neutrophils and macrophages (Hoşnuter et al., 2004; Parihar et al., 2008). Remarkably, oxidative compounds could also lead to the activation of receptors involved in pain transduction, such as transient receptor potential ankyrin 1 (TRPA1) (Hoşnuter et al., 2004; Parihar et al., 2008; Raisinghani et al., 2011).

The TRPA1 channel is a polymodal cellular sensor, which forms a non-selective cation channel, being permeable mainly to calcium (Levine and Alessandri-Haber, 2007). This receptor is expressed in peptidergic sensory fibers along TRP vanilloid 1 (TRPV1) (Geppetti et al., 2008). Moreover, TRPA1 is the primary target of many different irritant stimuli, such as allyl isothiocyanate (AITC, contained in mustard oil and wasabi) or cinnamaldehyde (present in cinnamon), and a series of endogenous oxidant molecules produced at sites of inflammation and tissue injury, such as reactive oxygen (ROS, as hydrogen peroxide) and nitrative (RNS) species (Andersson et al., 2008; Baraldi et al., 2010; Sawada et al., 2008; Taylor-Clark and Undem, 2010; Trevisani et al., 2007). Thus, the interaction between the TRPA1 channel and these highly reactive compounds is of high relevance for the recognition of cellular damage, especially during inflammatory and neuropathic events (Bang and Hwang, 2009; Hinman et al., 2007; McGaraughty et al., 2010; Trevisan et al., 2016).

Also, TRPA1 is emerging as a significant nociceptive mechanism in a variety of inflammatory pain models such as those induced by carrageenan, formalin, and complete Freund adjuvant injection (da Costa et al., 2010; Eid et al., 2008; McGaraughty et al., 2010; Petrus et al., 2007) or gout models (Moilanen et al., 2015; Trevisan et al., 2013, 2014). Previously, it was described that TRPV1 and TRPA1 could be activated by lipid oxidized agonists in the spinal cord after burn injury producing mechanical and thermal hypersensitivity (Green et al., 2016), however, to the best of our knowledge, the role of peripheral TRPA1 in burn-induced nociception was not investigated until now. It is well known that TRPA1 is activated by reactive species and sensitized by inflammatory mediators, being able to participate in the maintenance of the inflammatory pain process (Eid et al., 2008; McGaraughty et al., 2010; Petrus et al., 2007). Moreover, the effect of a topical TRPA1 antagonist in an inflammatory model of pain has not been observed yet. As the model of burn injury in rats produce an inflammatory reaction that could be treated locally, we choose this model to test the possibility that blocking the TRPA1 in the periphery could be sufficient to reduce the burn-induced nociception and inflammation. Regarding this, the current study aimed to evaluate the effect of a TRPA1 antagonist topical treatment in the nociception and inflammation induced by a thermal lesion model in the hind paw of rats.

\section{Material and methods}

\subsection{Animals}

Experiments were performed in adult male Wistar rats (150-200 g, 8-10 weeks) bred in-house. The animals were kept in ventilated cages (5 per cage) with wood shaving bedding and nesting material at controlled temperature $\left(22 \pm 2{ }^{\circ} \mathrm{C}\right)$ and a $12 \mathrm{~h}$ light/dark cycle (lights on 7:00 a.m. to 7:00 p.m.). It was provided the laboratory standard animal's food (Puro Lab 22 PB pelleted form, Puro Trato, Rio Grande do Sul, Brazil) and tap water ad libitum. The animals were habituated in the experimental room for at least $1 \mathrm{~h}$ before each behavioral task. The experiments reported in this study were performed according to the ethical guidelines to investigate pain-like symptoms in conscious animals set by the International Association for the Study of Pain (Zimmermann, 1983). The study was approved by the Committee on the Use and Care of Laboratory Animals at University of the Extreme South of Santa Catarina (Unesc), under protocol number 020/2015-2 with an addendum to the protocol, number 008/2015-2. The behavioral studies followed the Animal Research: Reporting In Vivo Experiments (ARRIVE) guidelines (McGrath and Lilley, 2015). The experimenter was blinded to drug administration. The protocol of thermal injury model in this study was repeated twice in different days of experiments (using two blocks of animals, one with 4 animals, and another with 3 animals per treated group), but each animal was used only one time. The experiments were performed between 7:00 a.m. and 5:00 p.m.

\subsection{Reagents}

Otherwise indicated, reagents were acquired from Sigma-Aldrich Chemical Co. (St. Louis, MO, USA). The treatments (HC-030031 or silver sulfadiazine) were incorporated into Lanette cream (Lanette ${ }^{\circledast}$ wax $12.0 \mathrm{~g}$; solid vaseline $11.0 \mathrm{~mL}$, propyleneglycol $7.0 \mathrm{~mL}$; parabens solution preservative $3.3 \mathrm{~g}$; imidazolidinyl urea preservative solution $50 \%$; distilled water for $100 \mathrm{~g}$ ) (Silva et al., 2013). Lanette cream (base cream) without HC-030031 was used as vehicle and silver sulfadiazine in the $1 \%$ concentration was used as a positive control (Silva et al., 2013; Souza et al., 2017). The HC-030031 was tested at three different concentrations $(0.005,0.05$, and $0.5 \%)$ based on concentrations that we have previously subcutaneously injected in the hind paw (Trevisan et al., 2013).

\subsection{Nociception and edema model induced by intraplantar injection of} AITC

Firstly, to determine the indicated concentration of HC-030031 (a TRPA1 antagonist) to be used in the thermic injury model, we used the AITC-induced nociception and edema model (Trevisan et al., 2013). For that, we performed an initial set of experiments where each animal received $200 \mathrm{mg}$ /paw of base cream containing HC-030031 and control group received only base cream. Animals were topically treated (right hind paw, $10 \mathrm{~min}$ before the test) with a base cream containing HC$030031(0.005$; 0.5 or $0.5 \%)$. The animals were divided into four groups (base cream, base cream containing $0.005 \%$ of HC-030031, base cream containing $0.05 \%$ of HC-030031, or base cream containing $0.5 \%$ of HC-030031) with five animals in each group. After $10 \mathrm{~min}$ of the topical administration, AITC was injected subcutaneously at a dose of $1 \mathrm{nmol} /$ paw ( $100 \mu \mathrm{L}$ volume) into the right hind paw. The nociceptive behavior (paw licking or flinching) was timed for 5 min after AITC injection. Also, $15 \mathrm{~min}$ after AITC injection, the paw edema was measured using a digital caliper as described before (Trevisan et al., 2013). Because the base cream containing $0.05 \%$ of HC-030031 reduced AITCinduced nociception and edema, we used this HC-030031 formulation to perform the further experiments using the thermal injury model in rats. 


\subsection{Thermal injury model}

Rats received a scald burn on the right hind paw as described previously (Gao et al., 2010; Silva et al., 2013). Following the measurement of baseline responses, the animals were anesthetized with ketamine ( $90 \mathrm{mg} / \mathrm{kg}$, i.p.) and xylazine ( $3 \mathrm{mg} / \mathrm{kg}$, i.p.) (Klafke et al., 2016), and the right hind paw was placed and held in $70^{\circ} \mathrm{C}$ water for $5 \mathrm{~s}$ (considered as a first burn model). In the sham procedure group (control group), the right hind paw was exposed to $37^{\circ} \mathrm{C}$ water for $5 \mathrm{~s}$. After the stimulus was applied, the rat was returned to the home cage to recover from anesthesia. The nociceptive behavior and paw edema were measured on days 1 to 6 after the induction of thermal injury or in the control group. The treatments were performed immediately after the injury (day 0 ), and then for a further 5 days period, and there was no treatment on the 6th day after the thermal injury. For the treatment, rats were divided into five groups ( $n=7$ animals for each group) known as Control (no injury); No treatment (thermal injury without treatment); Vehicle (thermal injury plus base cream); Sulfadiazine 1\% (thermal injury plus base cream containing silver sulfadiazine 1\%); and HC- $0300310.05 \%$ (thermal injury plus base cream containing HC$0300310.05 \%)$.

\subsection{Nociception assessment}

The antinociceptive effect of treatments tested was evaluated through several nociceptive parameters: static mechanical allodynia, dynamic mechanical allodynia, thermal allodynia, and spontaneous nociception. The nociception was measured before (baseline values) and once a day, from day 1 to 6 after thermal injury (Fig. 1).

\subsubsection{Static mechanical allodynia}

To estimate the static mechanical allodynia, rats were individually placed in clear Plexiglas boxes $(9 \mathrm{~cm} \times 7 \mathrm{~cm} \times 11 \mathrm{~cm})$ on elevated wire mesh platforms to access the ventral surface of the hind paws (Chaplan et al., 1994; Silva et al., 2013). The 50\% withdrawal threshold was determined using the up-and-down method (Dixon, 1980). In this paradigm, the test was initiated with the $6 \mathrm{~g}$ von Frey filament. We used seven distinct von Frey filaments: 15, 10, 8, 6, 4, 2 or $1 \mathrm{~g}$. Stimuli were always presented consecutively; either ascending or descending. Withdrawal thresholds were verified at several time points after thermal injury (from days 1 to 6 ) and were compared with the baseline values (before thermal injury). The results were expressed as noxious mechanical paw withdrawal threshold (s).

\subsubsection{Dynamic mechanical allodynia}

The dynamic response to a non-noxious mechanical stimulus was measured as described previously (Jaggi and Singh, 2011; Silva et al., 2013). The response to a soft paintbrush has been described as allodynia because naive rats rarely withdraw the paw from this stimulus. Rats were placed in clear Plexiglas boxes $(9 \mathrm{~cm} \times 7 \mathrm{~cm} \times 11 \mathrm{~cm})$ on elevated wire mesh platforms to access the ventral surface of the hind paws. After that, a smooth paintbrush stimulus was used to rub the plantar area of hind paw from the heel to the toes for a maximum of $15 \mathrm{~s}$. A paw withdrawal response within $15 \mathrm{~s}$ was considered as dynamic mechanical allodynia. The results were expressed as innocuous mechanical paw withdrawal latency (s).

\subsubsection{Thermal heat allodynia}

The paw immersion test was used to observe the response of rats to non-noxious heat. Briefly, rats were gently handled, and their right paw was dipped into a bath containing water at $30^{\circ} \mathrm{C}$ (Silva et al., 2013; Takahashi et al., 2003). The paw withdrawal latency was recorded with a chronometer. The maximum exposure to the stimulus time was $20 \mathrm{~s}$. The results were expressed as noxious thermal paw withdrawal latency (s).

\subsubsection{Spontaneous nociception}

The spontaneous nociceptive behavior of rats was evaluated for 5 min with a chronometer (Silva et al., 2013; Weissman-Fogel et al., 2008). The nociceptive response was determined as paw licking or flinching. Rats were placed in transparent acrylic boxes $(20 \mathrm{~cm} \times 20 \mathrm{~cm} \times 20 \mathrm{~cm})$ to observe the spontaneous nociception time.

\subsection{Inflammation and oxidative stress assessment}

\subsubsection{Edema development}

The paw edema induced by thermal injury was considered as the paw thickness increase, measured with a digital caliper (Silva et al., 2013; Trevisan et al., 2013). Paw thickness was verified at several time points ( 1 to 6 days) after thermal injury and compared to baseline values (before thermal damage). The results were expressed as paw thickness (mm). The caliper position was done in all the measures in the center of the hind paw, and the same experimenter observed the paw thickness in all time points.

\subsubsection{Parameters of inflammation and oxidative stress}

After 6 days of the thermal injury induction, the animals were euthanized by chemical method (pre-anesthetized with diazepam $5 \mathrm{mg}$ / $\mathrm{kg} / \mathrm{mL}$ and after that was administered thiopental $50 \mathrm{mg} / \mathrm{kg} / \mathrm{mL}$ i.p.). The samples of rats hind paw skin (we used the hind paw inferior surface) were removed to evaluate inflammatory and oxidative stress parameters and were processed separately for each analysis. We tested the animals until the 6th day after lesion because in previous studies of our group we observe that in this time point we could analyze the markers of inflammation and oxidative stress, after 6 days we noted a reduction in these parameters (Silva et al., 2013).

\subsubsection{Leukocyte infiltration markers}

To estimate the leukocyte infiltration after thermal injury, paw skin samples were collected to measure the myeloperoxidase (MPO) and $\mathrm{N}$ acetyl- $\beta$-D-glucosaminidase (NAGase) activities. Firstly, samples were obtained and homogenized with a motor-driven homogenizer in sodium acetate buffer containing $0.5 \% \mathrm{HTAB}$ and kept at $4{ }^{\circ} \mathrm{C}$, centrifuged and the supernatant was then collected for assays. For the MPO activity measurement, the supernatant was incubated with acetate buffer and $3,3^{\prime} 5,5^{\prime}$ tetramethyl-benzidine for $3 \mathrm{~min}$ at $37^{\circ} \mathrm{C}$. The color formed was assessed by a spectrophotometer at $630 \mathrm{~nm}$. For the measurement of NAGase activity, the supernatant was incubated with 4-nitrophenyl $\mathrm{N}$ acetyl- $\beta$-D-glucosaminide and citrate buffer at $37^{\circ} \mathrm{C}$ for $1 \mathrm{~h}$. The reaction was stopped by ice and with glycine buffer, and color development

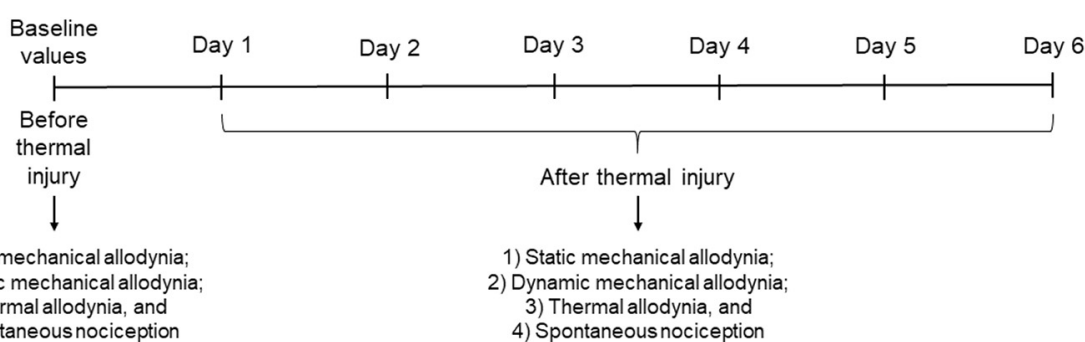

Fig. 1. Timeline of the nociception evaluation performed before the thermal injury in rats to assess the baseline values of nociceptive parameters and timeline from day 1 to 6 after thermal injury. The rats were evaluated daily through several nociceptive parameters as the following sequence: (1) Static mechanical allodynia, (2) Dynamic mechanical allodynia, (3) Thermal allodynia, and (4) Spontaneous nociception. 
was measured at $405 \mathrm{~nm}$. The absorbance of all reactions was measured in a Fisher Biotech Microkinetics Reader Bt 2000 microplate reader. The values were expressed as optical densities, corrected for the protein content, which was measured according to Bradford (1976).

\subsubsection{Histology}

Paw samples were collected and fixed for $14-16 \mathrm{~h}$ in alfac solution (16:2:1 mixture of ethanol $80 \%$, formaldehyde $40 \%$, and acetic acid). Samples were embedded in paraffin wax, sectioned at $4 \mu \mathrm{m}$ and stained with hematoxylin-eosin (H\&E). A representative area was selected for qualitative light microscopic analysis of the inflammatory cells detection with a $200 \times$ and $400 \times$ objectives under an optical microscope (Eclipse 50i, Nikon, Melville, NY). The images were recorded with the Nikon (Sight DS-5 M-L1, Melville, NY, USA). For the inflammatory cell count, six random fields from $\mathrm{H} \& E$-stained slides were observed to quantify the inflammatory cells (polymorphonuclear leukocytes) presence in dermis layer at the paw tissue using NIH Image J 13.6 software (NIH, Bethesda, MD, USA) at a magnification of $200 \times$ (Chibli et al., 2014; Lee et al., 2013; Oliveira et al., 2014; Song et al., 2008). The results were expressed as number of polymorphonuclear cells per field.

2.6.5. Determination of hydrogen peroxide levels, NADPH oxidase and superoxide dismutase (SOD) activity

The samples were homogenized in phosphate buffer, containing sodium azide at $4{ }^{\circ} \mathrm{C}$ for $30 \mathrm{~s}$. The homogenate was centrifuged and the supernatant obtained was used to determine the $\mathrm{H}_{2} \mathrm{O}_{2}$ levels (Nakamura et al., 1998; Trevisan et al., 2013). The $\mathrm{H}_{2} \mathrm{O}_{2}$ levels were expressed as $\mu \mathrm{mol}$ of $\mathrm{H}_{2} \mathrm{O}_{2}$, based on a standard curve of HRPO-mediated oxidation of phenol red by $\mathrm{H}_{2} \mathrm{O}_{2}$, and corrected by the protein content (in $\mathrm{mg}$ ) of the paw skin sample analyzed (Bradford, 1976).

The activity of NADPH-oxidase was observed in paw skin samples using a commercially available assay kit (CY0100, cytochrome reductase, NADPH Assay Kit, Sigma-Aldrich). The results were expressed as $\mathrm{U} / \mathrm{mL} / \mathrm{mg}$ of protein (Bradford, 1976).

To analyze the SOD activity (Bannister and Calabrese, 1987), paw skin samples were homogenized in Tris-HCl buffer and centrifuged at $4{ }^{\circ} \mathrm{C}$ for $3 \mathrm{~min}$. Then, the samples were incubated with adrenaline and glycine buffer at $33^{\circ} \mathrm{C}$. The absorbance was measured at $480 \mathrm{~nm}$ and monitored for $5 \mathrm{~min}$. The reaction was read in a microkinetic reader (Fisher Biotech BT, 2000). The results were expressed as $\mathrm{U} / \mathrm{mL} / \mathrm{mg}$ of protein, and protein content was measured by the method of Bradford (1976).

\subsection{Statistical analysis}

All values were expressed as mean \pm S.E.M and analyzed by Student's $t$-test, one-way or two-way analysis of variance (ANOVA) followed by Bonferroni's post hoc test when appropriate. All analyzes were carried out using GraphPad 5.0 Software (San Diego, CA, USA) and ImageJ software (western blot and inflammatory cells count). The $P<0.05$ values denote significant difference between groups.

\section{Results}

\subsection{Topical application of HC-030031 decreased nociception and edema caused by AITC intraplantar administration}

It was observed that a base cream containing HC-030031 0.05 and $0.5 \%$ ) decreased the nociceptive and edematogenic responses evoked by intraplantar injection of the TRPA1 agonist (AITC, $1 \mathrm{nmol} / \mathrm{paw}$ ), with a inhibition of $72 \pm 13$ and $76 \pm 6 \%$ for the nociception, and $76 \pm 8$ and $60 \pm 8 \%$ to the edematogenic effect, respectively (Fig. 2A and $\mathrm{B})$. As no significant differences were identified between these two concentrations, the base cream containing HC-030031 (0.05\%) formulation was chosen to perform further the study of TRPA1 antagonist effect on the inflammatory pain model caused by thermal injury in rats.
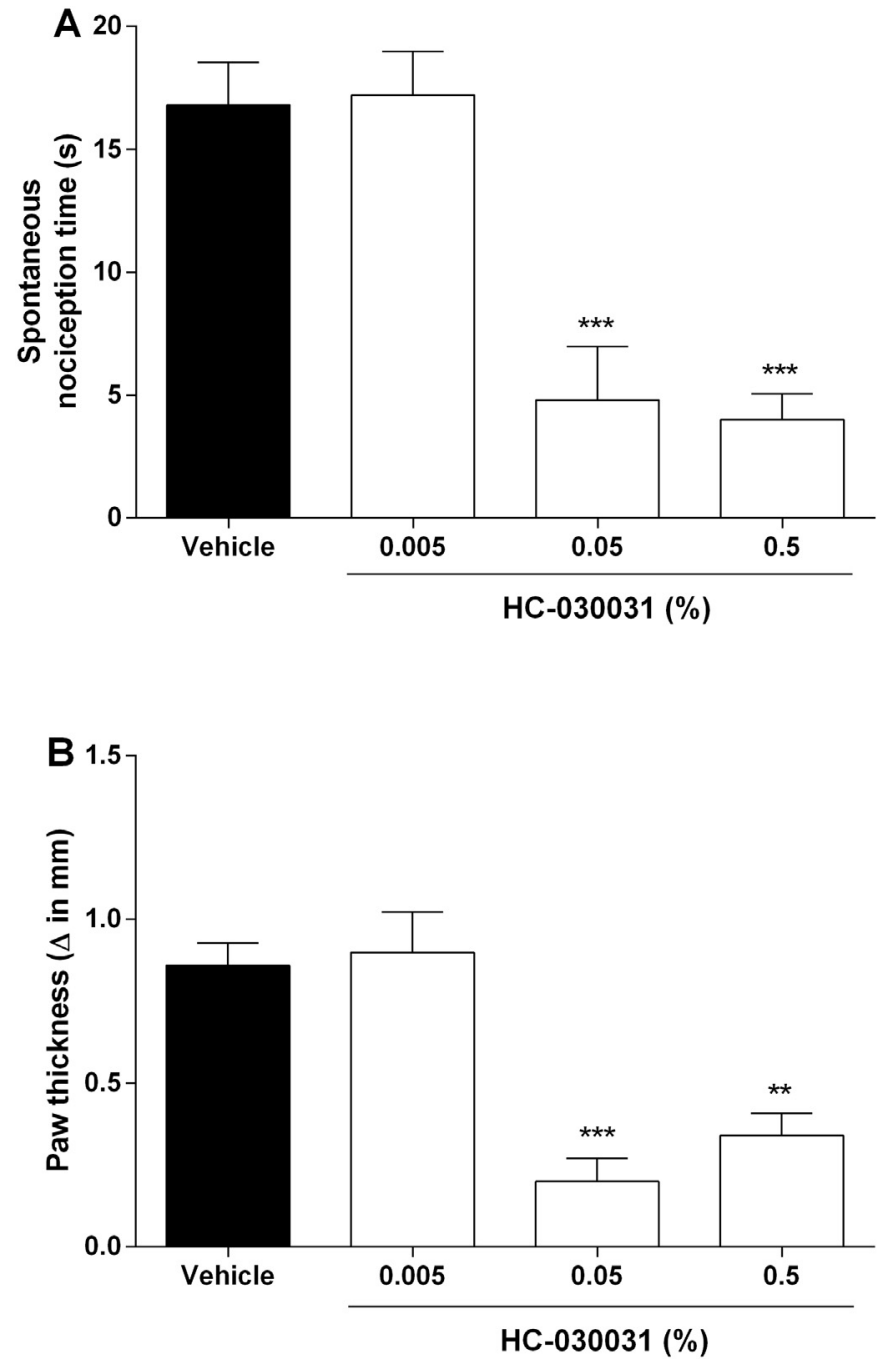

Fig. 2. (A) Antinociceptive or (B) antiedematogenic effect of a TRPA1 antagonist (HC-030031) by topical treatment after the intraplantar injection of AITC in rats. AITC (a TRPA1 agonist, $1 \mathrm{nmol} / \mathrm{site}$ ) was injected $10 \mathrm{~min}$ after the topical administration of base cream (vehicle, $200 \mathrm{mg} / \mathrm{paw}$ ) or base cream containing HC-030031 (0.005, 0.05, and 0.5\%). Data are expressed as mean \pm S.E.M. $(n=5) .{ }^{*} P<0.01$ and ${ }^{*} * * P<0.001$ when compared to the vehicle-treated group (One-way ANOVA followed by Bonferroni's test).

\subsection{TRPA1 antagonism induced antinociceptive effects in a thermal injury model in rats}

After thermal injury induction, static mechanical allodynia was detected from day 1 to 6 , when compared to control animals. It was characterized by a reduction in the paw withdrawal threshold evaluated through von Frey filaments $(15 \mathrm{~g}$ for control group vs. $1.32 \mathrm{~g}$ for no treated group, observed on day 6 after thermal injury; Fig. 3A). Furthermore, rats that received topic treatment with HC-030031 $(0.05 \%)$ showed an anti-allodynic effect from day 4 to 6 after treatment, with an inhibition of $43 \pm 10 \%$ on the 6th day after thermal injury (Fig. 3A). Silver sulfadiazine (1\%) demonstrated a similar efficacy when compared to HC-030031 treatment, which presented an inhibition of $44 \pm 15 \%$, at 6 days after the thermal injury (Fig. 3A).

In comparison to the control group, the rats that received thermal injury and were not treated showed dynamic mechanical allodynia (from 1 day to 6). Thus, animals with thermal injury but without treatment reduced the paw withdrawal latencies in response to a paintbrush ( $15 \mathrm{~s}$ for control group vs. $4.85 \mathrm{~s}$ for no treated group, observed on day 5 after thermal injury; Fig. 3B). Also, application of HC- 

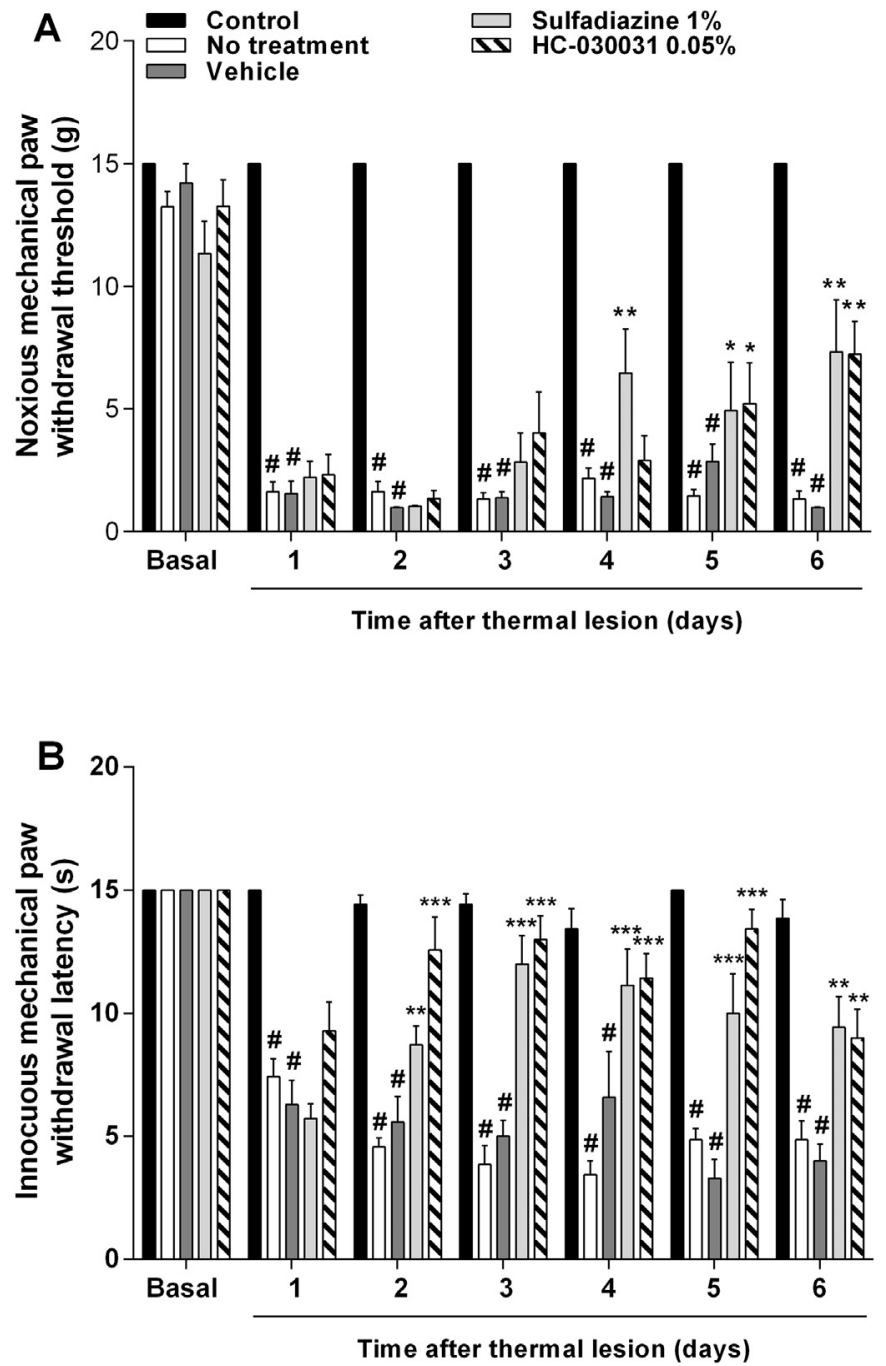

Fig. 3. Time-course of the TRPA1 antagonist (HC-030031) topical treatment on (A) static mechanical allodynia or (B) dynamic mechanical allodynia induced by thermal injury in rats. Silver sulfadiazine $1 \%$ was used as positive control in this model of inflammatory pain. The animals were divided into the following groups: Control (no thermal injury induction), No treatment (thermal injury without topical treatment, Vehicle (thermal injury and treated with base cream), HC-030031 $0.05 \%$ (thermal injury and treated with base cream containing HC-030031), and Sulfadiazine 1\% (thermal injury and treated with base cream containing silver sulfadiazine). Nociception was measured before (baseline values) and once a day from day 1 to 6 after thermal injury. Data are expressed as mean \pm S.E.M. $(n=7) . \quad * P<0.05 ; * * P<0.01$, and ${ }^{* * *} P<0.001$ when compared to the no treatment or vehicle (base cream) treated groups. ${ }^{\#} P<0.001$ when compared to control group (Two-way ANOVA followed by Bonferroni's test).

030031 or silver sulfadiazine reduced dynamic mechanical allodynia from 2 until 6 days after the thermal injury, with an inhibition of $89 \pm 5 \%$ and $67 \pm 11 \%$, respectively on the 5th day after thermal injury (Fig. 3B).

Also, it was observed the development of thermal allodynia from 1 day until 6 days after thermal injury (with mean values of $12.4 \mathrm{~s}$ for the control group and $3.5 \mathrm{~s}$ for the group with the thermal injury without treatment at 6 days after lesion; Fig. 4A). It was observed the antinociceptive effect of HC-030031 or silver sulfadiazine from day 3 to 6 , after injury ( $47 \pm 6 \%$ and $57 \pm 6 \%$ of inhibition, respectively, on day 6 after thermal injury; Fig. 4A).

Furthermore, thermal injury caused spontaneous nociception from day 1 until day 6 after injury (2.42 s for control group vs. $17.28 \mathrm{~s}$ for no
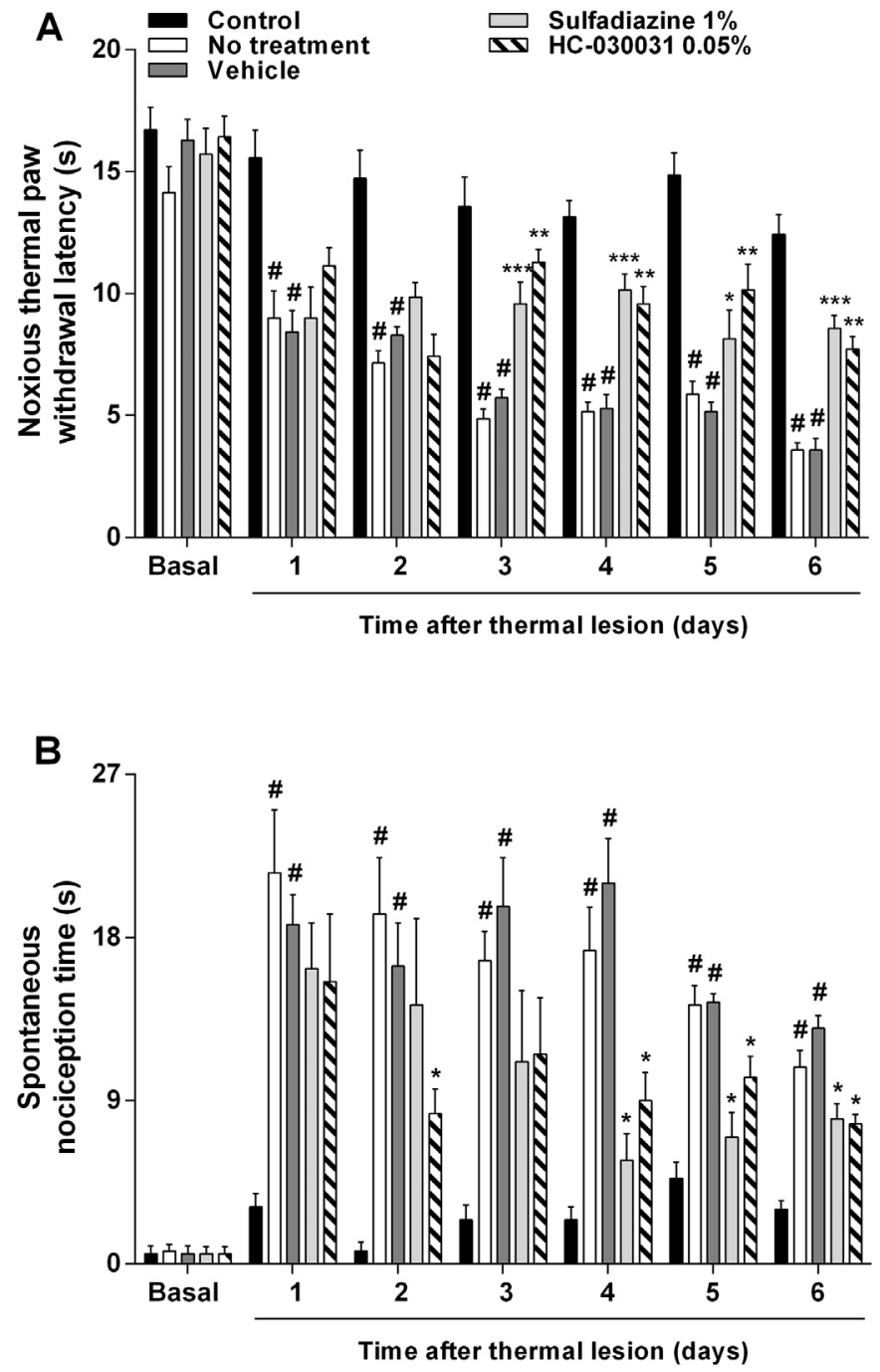

Fig. 4. Time-course of the topical treatment using a TRPA1 antagonist (HC030031) on (A) thermal allodynia or (B) spontaneous nociception induced by thermal injury in rats. Silver sulfadiazine $1 \%$ was used as positive control. Nociception was measured before (baseline values) and once a day from day 1 to 6 after thermal injury. Data are expressed as mean \pm S.E.M. $(\mathrm{n}=7)$. ${ }^{*} P<0.05 ;{ }^{* *} P<0.01$, and ${ }^{* * *} P<0.001$ when compared to the no treatment or vehicle-treated groups. ${ }^{\#} P<0.001$ when compared to control group (Two-way ANOVA followed by Bonferroni's test).

treated group, observed on day 4 after thermal injury; Fig. 4B). Also, it was observed that treatment with HC-030031 reduced the spontaneous pain induced by thermal injury on days 2,4 ( $48 \pm 9 \%$ inhibition), 5 and 6 after injury (Fig. 4B). Also, silver sulfadiazine presented antinociceptive effect on day 4 (67 $\pm 8 \%$ inhibition), 5 , and 6 after injury (Fig. 4B). The topical treatment with the base cream (vehicle) did not alter static, dynamic, thermal allodynia or spontaneous nociception induced by thermal injury model (Figs. 3 and 4).

\subsection{Base cream containing HC-030031 induced anti-inflammatory effects in a thermal injury model}

The animals that received the thermal injury and did not receive treatment presented edema characterized by paw thickness increase, when compared to the control group (no injury), with mean $5.5 \mathrm{~mm}$ and $0.42 \mathrm{~mm}$, respectively ( 6 days after the lesion; Fig. 5A). Topical application of the base cream (vehicle) did not promote antiedematogenic effect. However, topical treatment with HC-030031 reduced the edema formation caused by thermal injury from day 1 until 

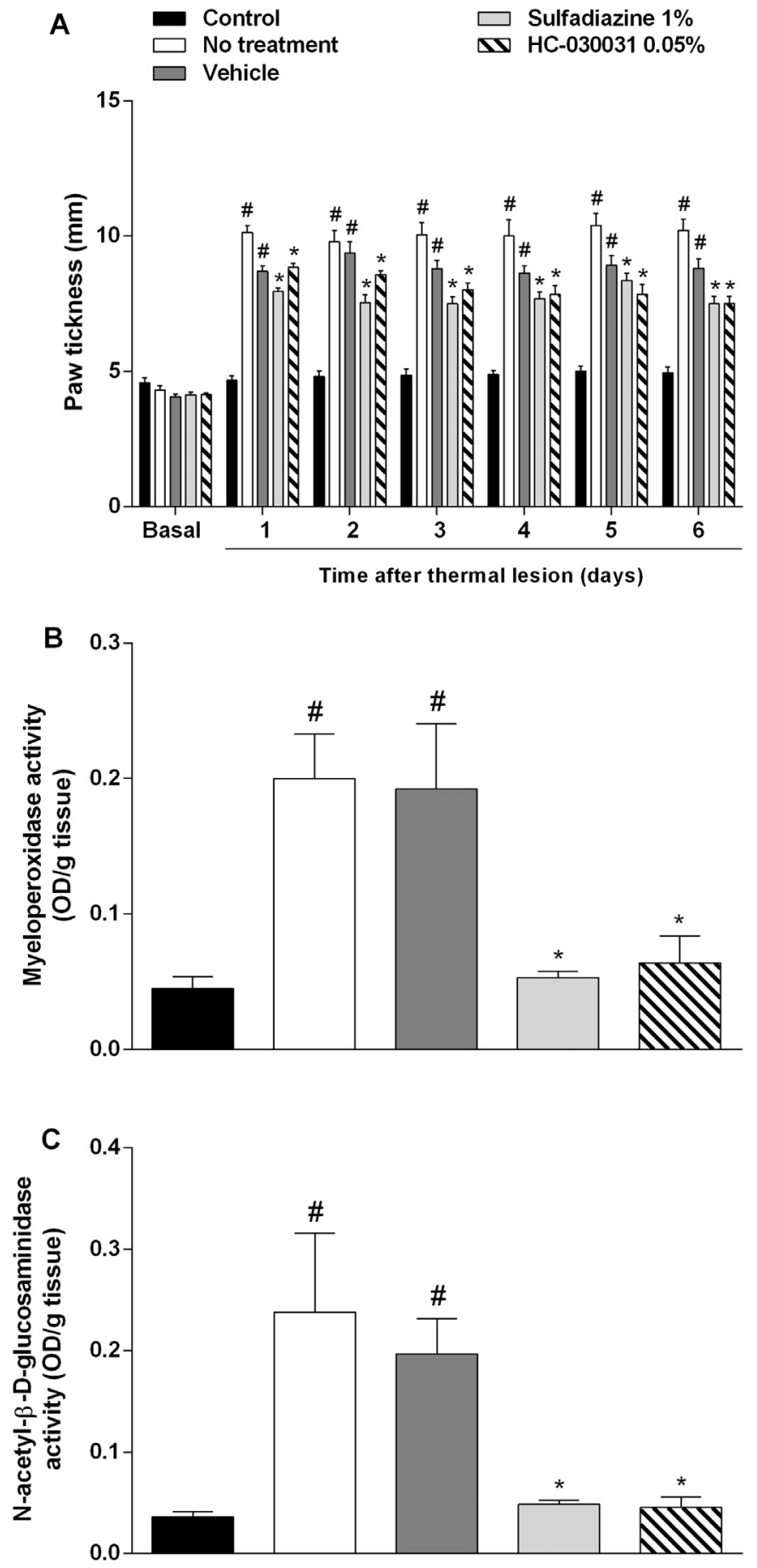

Fig. 5. (A) Time-course of the topical treatment with a base cream containing HC-030031 $(0.05 \%)$ on paw edema induced by thermal injury in rats. Silver sulfadiazine $1 \%$ was used as positive control. Paw edema was measured before (baseline values) and once a day from day 1 to 6 after thermal injury. Data are expressed as mean \pm S.E.M. $(n=7$; Two-way ANOVA followed by Bonferroni's test). (B) Myeloperoxidase or (C) $N$-acetyl- $\beta$-D-glucosaminidase activities observed in the skin hind paw tissue at 6 days after the thermal injury or control groups. Data are expressed as mean \pm S.E.M. $(n=5-7)$. ${ }^{*} P<0.05$ when compared to the no treatment or vehicle-treated groups. ${ }^{\#} P<0.001$ when compared to control group (One-way ANOVA followed by Bonferroni's test).

day 6 after thermal injury with an inhibition of $46 \pm 5 \%$ at day 6 after thermal injury). Also, the application of silver sulfadiazine reduced edema formation from 1 to 6 days after thermal injury with an inhibition of $46 \pm 5 \%$ at 6 days after thermal injury (Fig. 5A).

Also, we evaluated the MPO and NAGase activities in the hind paw skin tissue at 6 days after thermal injury. The thermal injury increased the MPO and NAGase activities when compared with the control group (Fig. 5B and C). The base cream (vehicle) treatment did not reduce the MPO and NAGase activities. However, HC-030031 or silver sulfadiazine decreased these inflammatory parameters with an inhibition of $68 \pm 10$ and $73 \pm 2 \%$ for MPO activity, and $79 \pm 5$ and $80 \pm 2 \%$ for NAGase activity, respectively (Fig. 5B and C).

Furthermore, we performed the histological analysis to confirm the leukocyte infiltration at the paw tissue, at 6 days after thermal injury. Here, we observed that thermal injury increased the leukocyte infiltration at the paw skin tissue when compared to the control group (Fig. 6). The number of infiltrated inflammatory cells was significantly lower in the groups treated with HC-030031 or silver sulfadiazine, with an inhibition of $76 \pm 2 \%$ and $82 \pm 4 \%$, respectively. However, the topical treatment with the base cream (vehicle) did not decrease the number of infiltrated inflammatory cells (Fig. 6).

\section{4. $\mathrm{H}_{2} \mathrm{O}_{2}$ content, NADPH oxidase, and SOD activity were reduced by $\mathrm{HC}$ - 030031 treatment in a thermal injury model}

The thermal injury increased the $\mathrm{H}_{2} \mathrm{O}_{2}$ content, and the NADPH oxidase and SOD activities when compared to the control group (Fig. 7A, B, and C). Moreover, the groups treated with HC-030031 or silver sulfadiazine reduced all oxidative parameters evaluated, with an inhibition of $71 \pm 6$ and $69 \pm 10 \%$ to $\mathrm{H}_{2} \mathrm{O}_{2}$ levels; $60 \pm 7$ and $66 \pm 10 \%$ to NADPH oxidase activity and $68 \pm 7$ and $67 \pm 7 \%$ to SOD activity, respectively (Fig. 7A, B, and C). However, topical treatment with the base cream did not reduce these oxidative stress parameters after thermal injury (Fig. 7A, B, and C).

\section{Discussion}

The pain observed in patients with a burn is often disabling and can lead to different psychological conditions even after recovery (Xie et al., 2012). Until now, there are no drugs that effectively act in all sorts of pain, because these treatments may be related to adverse effects development (McIntyre et al., 2016). Thus, it is necessary to search for novel mechanisms that could be associated with pain caused by thermal injuries, and which may aid in the development of the new treatments (Chang and Waxman, 2010; Fowler et al., 2014; Silva et al., 2014; Ueda et al., 2014). Here, we assessed the topical analgesic effect of a base cream containing a TRPA1 antagonist. The topical treatment using a TRPA1 antagonist exerted antinociceptive and anti-inflammatory effects, and it shows the relevant role of the peripheral TRPA1 channel in this model of inflammatory pain.

In this sense, several animal models of thermal lesion have been developed to evaluate the analgesic and anti-inflammatory effects of compounds in mice and rats (McIntyre et al., 2016). The pain model induced by high-temperature water burn has been used in previous studies, and it has an interesting approach because no extensive lesion is generated in the animal by this model. Besides, this thermal injury model presents an inflammatory action limited to the affected area (Jeschke et al., 2009), leading to nociception in the hind paw, an easily accessible hairless site to evaluate the nociception parameters (Barrot, 2012). So far, no studies have been done with a topical formulation containing TRPA-specific antagonists such as HC-030031. In previous studies, TRPA1 antagonists were locally injected in models of neuropathic and inflammatory pain, showing antinociceptive activity without induction of adverse effects (Pinheiro et al., 2015; Trevisan et al., 2016, 2014). So, in the current study, the acute pain model induced by administration of AITC (a TRPA1 agonist) (Trevisan et al., 2014) was chosen to determine the possible antinociceptive effect of topical application of a base cream containing HC-030031.

Moreover, we may suggest that HC-030031 incorporated in the base 


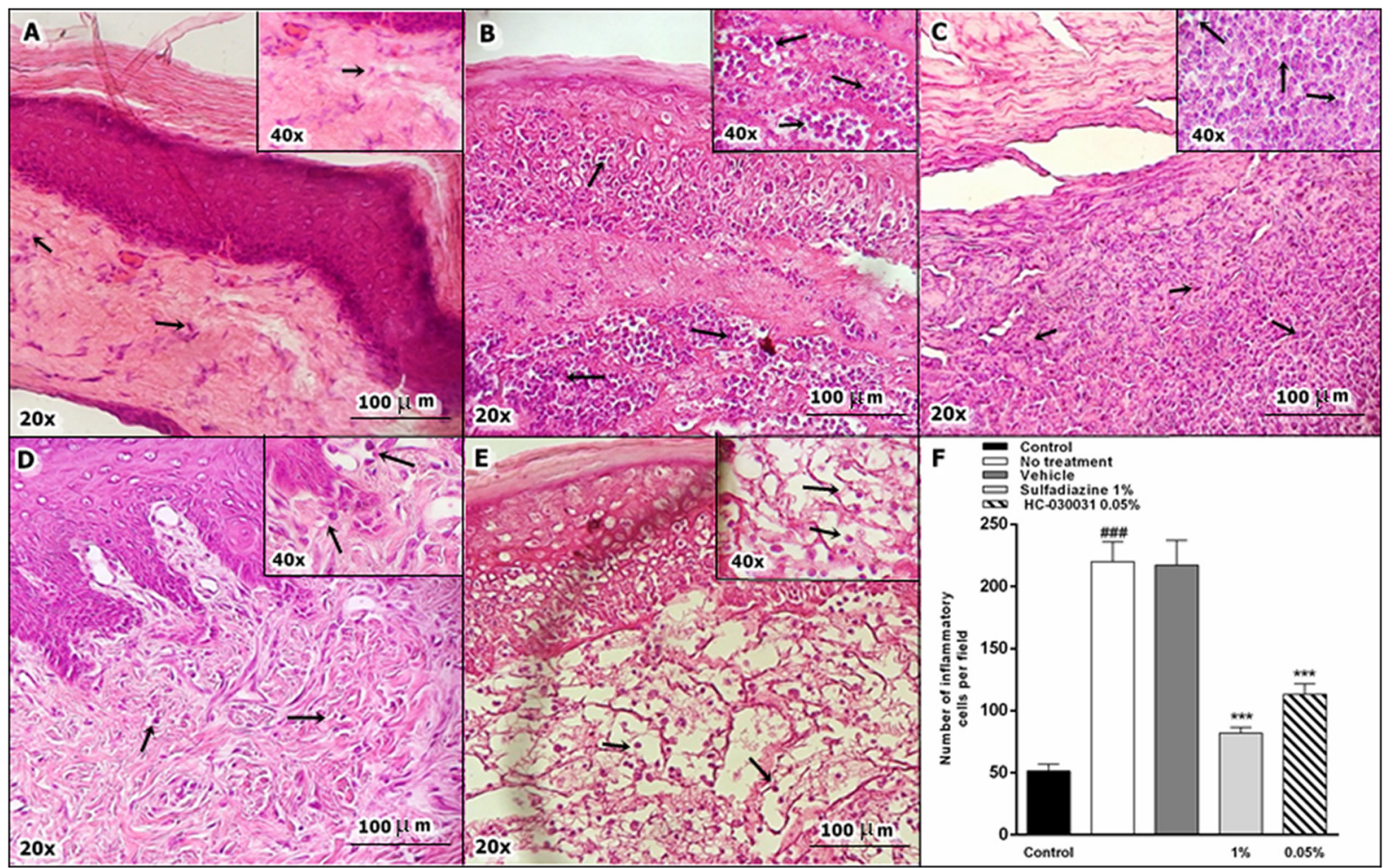

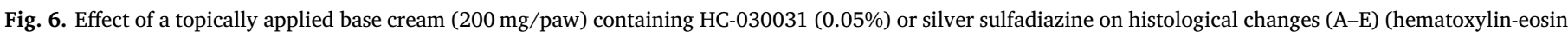

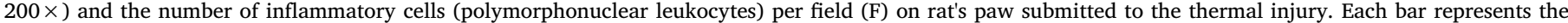

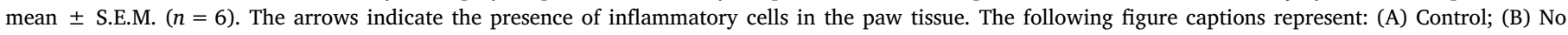

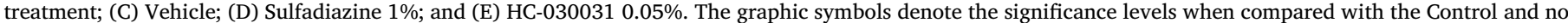

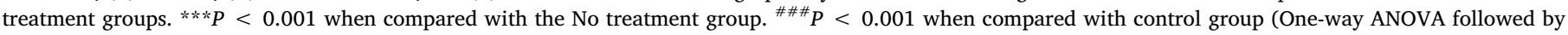
Bonferroni's test). Scale bar, $100 \mu \mathrm{m}$.

cream formulation was responsible for the antinociceptive effect observed after burn injury because the topical treatment with only base cream (vehicle) did not reduce the nociceptive parameters evaluated when compared with control group. TRPA1 is not usually described as a mechanosensitive ion channel, but the injection of TRPA1 agonists may cause mechanical allodynia, which was reduced by TRPA1 antagonists (Griggs et al., 2017; Trevisan et al., 2013; Tsagareli et al., 2010). Moreover, several reports showed that TRPA1 antagonism might reduce mechanical allodynia in models of inflammatory and neuropathic pain (Andrade et al., 2012; Nassini et al., 2014).

A significant number of agents found in the inflammation site could sensitize TRPV1 and TRPA1 channels; then it is essential to reduce this process to observe an antinociceptive effect (Sousa-Valente et al., 2014). The TRPA1 receptor is normally found in sensory neurons that express TRPV1, a noxious heat sensor, so the antagonism of the TRPA1 by reducing inflammation could also decrease TRPV1 sensitization, thus reducing heat hyperalgesia (Gouin et al., 2017). Moreover, the injection of TRPA1 agonists may cause heat hypersensitivity, which was blocked by TRPA1 antagonists (Griggs et al., 2017; Tsagareli et al., 2010), and TRPA1 agonists also induced heat hypersensitivity in humans (Andersen et al., 2017; Namer et al., 2005). Moreover, it has been described that TRPV1, TRPM3 and TRPA1 function together with the detection of acute noxious heat (Vandewauw et al., 2018). Thus, possible in the model used in this study the TRPA1 antagonism has contributed to reducing TRPV1 sensitization by HC-030031 anti-inflammatory effect so that HC-030031 can decrease heat allodynia. However, it is relevant to note that other pain mechanisms were already described to be involved in burn pain, such as activation of TRPV1 and $\mathrm{P}_{2} \mathrm{X}_{2 / 3}$ receptors. Also, as the composition of burn injury is complex the attempt to find a leading compound produced in this fluid is complicated, but it is interesting to search for a group of receptors that could be activated at the site of injury (Laycock et al., 2013). The TRPA1 as indicated by our results could also be included as a target to reduce pain after burn injury, but it is difficult to sustain that is the sole mechanism in this pain pathology. Thus, we could hypothesize that as TRPA1 is a sensor for a myriad of harmful compounds produced after burning this could be highly activated causing calcium influx and neurogenic inflammation, then initially TRPA1 gating could create and maintain nociceptor sensitization.

Also, the TRPA1 antagonist ability in reducing spontaneous nociception was reported previously in a craniofacial muscle pain model (Asgar et al., 2015). A similar antinociceptive result had already been described for silver sulfadiazine $1 \%$ cream in the same model in rats (Silva et al., 2013). Silver sulfadiazine also showed positive results in these tests, which agrees with its analgesic effect described in the clinic (Nasiri et al., 2016; Shahzad and Ahmed, 2013). Although many studies demonstrated the adverse effects related to the silver sulfadiazine use, this treatment still being indicated to reduce the burn lesions (Andersson et al., 2008; Irimia et al., 2011; Labuz and Machelska, 2013). Systemic adverse effects such as renal toxicity and leukopenia are also described, suggesting that the use of silver sulfadiazine would not be indicated in long-term treatments (Andersson et al., 2008). Silver sulfadiazine is a standard topic treatment for partial burn injuries, the main reason to be used in the current study as a positive control (Abboud et al., 2014; Atiyeh et al., 2007; Marx and Barillo, 2014). Indeed, silver sulfadiazine is primarily used in burn injuries to induce antimicrobial effect, but it was already described that this compound could also reduce inflammation and nociception in animal models of thermal injury (Abboud et al., 2014; Nadworny et al., 2008; Piana et al., 2013; Silva et al., 2014).

Therefore, considering that the thermal injury model also causes continuous inflammation in the affected tissue, we also evaluated 

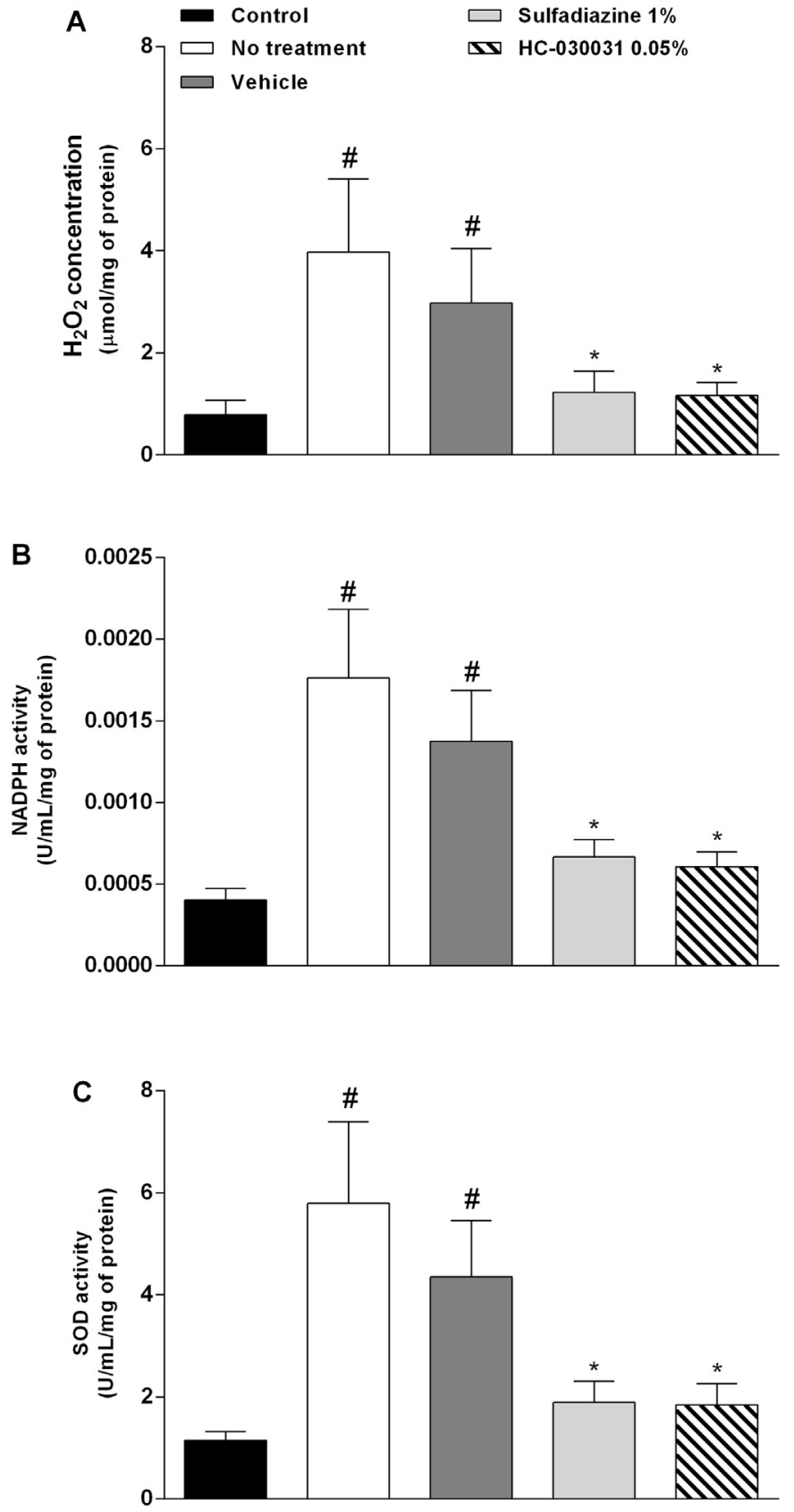

Fig. 7. Effects of the base cream containing HC-030031 (0.05\%) on (A) hydrogen peroxide concentration, or (B) NADPH and (C) SOD activities in a model of thermal injury in rats. Silver sulfadiazine $1 \%$ was used as positive control. Data are expressed as mean \pm S.E.M. $(n=5-7)$. ${ }^{*} P<0.05$ when compared to the no treatment or vehicle-treated groups. ${ }^{\#} P<0.001$ when compared to control group (One-way ANOVA followed by Bonferroni's test).

inflammatory parameters, such as paw edema (Silva et al., 2013). Edema can be induced by several factors including vasodilation, extravascular osmotic activity, and augmented microvascular permeability, which frequently accompanies inflammation after burn (Arturson, 2000; Rowan et al., 2015). However, excessive or prolonged edema and inflammation prejudice wound healing (Edgar et al., 2011; Sommer et al., 2013). In this sense, anti-inflammatory drugs also could aid in the pain and edema treatment (Walls et al., 2017). However, the long-term use of non-steroidal analgesics/anti-inflammatories or even corticosteroids implies not only loss of efficacy, but also adverse effects development, which limits their use (Irimia et al., 2011; Monteith and Goadsby, 2011; Paemeleire et al., 2006; Stovner et al., 2009).
Moreover, other burn treatments, such as morphine or gabapentin, are used because they present analgesic properties but lack of anti-inflammatory effects (Gamst-Jensen et al., 2014; McIntyre et al., 2016; Richardson and Mustard, 2009; Singer and Dagum, 2008). The HC030031 antiedematogenic effect was previously reported through oral or intraplantar administration (Trevisan et al., 2014). It was already described that TRPA1 activation causes the release of calcitonin generelated peptide (CGRP) or vascular endothelial growth factor (VEGF), and these mediators are involved in the increase of vascular permeability observed in burn damage (Gherardini et al., 2009; Siney and Brain, 1996; Infanger et al., 2004; Volpi et al., 2011).

After thermal lesion, neutrophils and macrophages infiltration to the lesion site is involved not only in the initiation and resolution steps of the acute inflammation but also chronic inflammation (Evers et al., 2010; Fullerton and Gilroy, 2016; Gamst-Jensen et al., 2014; Laycock et al., 2013; McIntyre et al., 2016; de Oliveira et al., 2016). However, an excessive inflammatory cell infiltration may contribute to the sensitization of nociceptors due to the continuous inflammatory mediator's production and release (Laycock et al., 2013; McIntyre et al., 2016; Summer et al., 2007). Here, we demonstrated that the thermal lesion model produced an inflammatory cells infiltration to the lesion site. Such findings were shown by the increase of enzymes markers of the neutrophil and macrophages infiltration (myeloperoxidase and NAGase, respectively), and confirmed by the histological sections of rats' paw tissue, results which were previously described by Silva et al. (2013). Previously, in models of acute inflammation, it was reported that TRPA1 antagonists could reduce the inflammatory process (da Costa et al., 2010; Eid et al., 2008; Horváth et al., 2016; McGaraughty et al., 2010; Petrus et al., 2007).

The TRPA1 is expressed in sensory terminals located in the dermis and epidermis, and its activation promotes the calcium influx induced by signs of damage, such as the excessive production of oxidizing substances, as hydrogen peroxide and 4-hydroxynonenal (4-HNE). Hydrogen peroxide has been linked to the development of different painful conditions in animal models of acute pain, such as in gout (Moilanen et al., 2015; Trevisan et al., 2013, 2014), inflammatory arthritis (Keeble et al., 2009; Moilanen et al., 2015), or neuropathic pain (Trevisan et al., 2016). Thus, many studies have demonstrated that the hydrogen peroxide production by tissue-resident cells (i.e., synoviocytes), macrophages and neutrophils, could favor the sensitization of nociceptors via TRPA1 activation (Moilanen et al., 2015; Trevisan et al., 2016, 2014). Previous studies reported that thermal burn might increase the reactive species production, which could contribute to the tissue damage (Bhatia et al., 2016; Hoşnuter et al., 2004; Parihar et al., 2008; Silveira et al., 2016; Tanaka et al., 1999). In this sense, antioxidants are designed to reduce production and to capture reactive species that promote tissue lesion (Wasiak et al., 2013). Besides, these treatments may be useful in the burn-induced pain reduction, as well as, in patients with systemic responses, allowing a longer time of patient survival and helping the necrotic tissue reduction in the wound (Lee et al., 2011; Rock et al., 1997). Thus, the TRPA1 channel could be activated by these oxidant compounds which would cause inflammation and nociception. Therefore, our findings showed altered oxidative status in the animals after thermal injury when compared to the controls. These findings may be associated with the anti-inflammatory effect of HC-030031 and silver sulfadiazine formulations because the reduced infiltration of inflammatory cells consequently decreases the reactive species production by these cells.

The mechanisms of post-burn pain are still not completely understood, but the thermal burn injury frequently induced pain by the inflammatory processes generated after the initial trauma. Moreover, this type of inflammatory pain is often associated to the presence of infiltrated leukocytes in the damaged skin and the constant release and production of distinct inflammatory and oxidant mediators (McIntyre et al., 2016; Laycock et al., 2013). The established capacity of TRPA1 to sense oxidative stress (Mori et al., 2016; Nassini et al., 2014; Andersson 
et al., 2008; Trevisani et al., 2007), led to the hypothesis that inflammatory pain is sustained by the oxidative burden generated by infiltrating leukocytes that continuously target TRPA1 in nerve fibers, causing nociception and inflammation. Thus, the blockage of this receptor could reduce calcium influx mediated by TRPA1 and the consequent neurogenic inflammation promoted by this receptor. It was already showed that the antagonism of the TRPA1 receptor could reduce inflammation and nociception in different models of inflammatory pain (Andrade et al., 2012; Nassini et al., 2014), thus this receptor has emerged as a potential drug target as it functions as a sensor for tissue damage and inflammation (Viana, 2016). In addition, some studies showed that TRPA1 activation by oxidant compounds may cause calcium influx inducing the activation of NADPH oxidase and production of intracellular reactive compounds that induce nuclear factor- $\kappa \mathrm{B}$ (NF$\kappa \mathrm{B})$ or/and mitogen-activated protein kinases (MAPKs) signaling (Lin et al., 2015; Lee et al., 2016). Then, this process could regulate the expression of inflammatory genes in the injured tissues, once we antagonize the TRPA1, the enhancement in NADPH oxidase activity and the increase in intracellular reactive oxygen species production are inhibited, which may reduce the further activation of NF-kB. Also, it was previously described that TRPA1 gene expression is induced via NF- $\mathrm{KB}$ signaling (Hatano et al., 2012). Also, it was studied that TRPA1 gating induces activation of mitogen-activated protein kinase (MAPK) (Kondo et al., 2013; Volpi et al., 2011; Lin et al., 2015). In this frame, therefore, it is possible that the antagonism caused a reduction of calcium influx through TRPA1 channels, which in turn prevent NF-kB/ MAPK activation during inflammatory responses.

Also, the afterburn neuropathic pain occurrence, accompanied or not by pruritus, is usually controlled with the use of non-opioid drugs such as gabapentin and amitriptyline, and it is a form of opioid resistant pain (McIntyre et al., 2016). However, these treatments are not effective in all patients and often cause adverse effects, which makes topical treatment an interesting alternative mainly related to pain observed in small- and medium-severity burns (Burgess and Williams, 2010; Evers et al., 2010; Labuz and Machelska, 2013). In this view, the use of a TRPA1 antagonism by the topical application could be combined with a systemic medication such as an anticonvulsant drug. Moreover, TRPA1 has been pointed as a mediator of itch in distinct models (Kittaka and Tominaga, 2017), so combining a TRPA1 antagonism by topical application with a systemic medication, could be useful to reduce inflammation and possible pruritus in burn patients.

In conclusion, this study presents results indicating the effect of TRPA1 antagonists on nociception and inflammation control in a thermal lesion model. Therefore, from the results currently obtained, the TRPA1 channel presents as a relevant and promising source for the development of new analgesics, which could be used for pain treatment, specially developed after thermal injury.

\section{Acknowledgments}

This study was supported by National Research Council of Brazil (CNPq; \#422376/2016-7). C.T.D.A., S.D.T.D.P., A.S.A., C.C., G.B.S. are recipients of fellowships from Coordination of Improvement of Higher Education Personnel (CAPES).

\section{Disclosure}

The authors declare no conflict of interest. None of the authors have received compensation for professional services in any of the previous years or anticipate receiving such compensation in the near future.

\section{Ethical approval}

All applicable international, national, and/or institutional guidelines for the care and use of animals were followed.

\section{References}

Abboud, E.C., Legare, T.B., Settle, J.C., Boubekri, A.M., Barillo, D.J., Marcet, J.E. Sanchez, J.E., 2014. Do silver-based wound dressings reduce pain? A prospective study and review of the literature. Burns 40, S40-S47. https://doi.org/10.1016/j. burns.2014.09.012.

Andersen, H.H., Lo Vecchio, S., Gazerani, P., Arendt-Nielsen, L., 2017. Dose-response study of topical allyl isothiocyanate (mustard oil) as a human surrogate model of pain, hyperalgesia, and neurogenic inflammation. Pain 158, 1723-1732. https://doi. org/10.1097/j.pain.0000000000000979.

Andersson, D.A., Gentry, C., Moss, S., Bevan, S., 2008. Transient receptor potential A1 is a sensory receptor for multiple products of oxidative stress. J. Neurosci. 28 , 2485-2494. https://doi.org/10.1523/JNEUROSCI.5369-07.2008.

Andrade, E.L., Meotti, F.C., Calixto, J.B., 2012. TRPA1 antagonists as potential analgesic drugs. Pharmacol. Ther. 133, 189-204. https://doi.org/10.1016/j.pharmthera.2011. 10.008 .

Arturson, G., 2000. Forty years in burns research - the postburn inflammatory response Burns 26, 599-604. https://doi.org/10.1016/S0305-4179(00)00069-3.

Asgar, J., Zhang, Y., Saloman, J.L., Wang, S., Chung, M.-K., Ro, J.Y., 2015. The role of TRPA1 in muscle pain and mechanical hypersensitivity under inflammatory conditions in rats. Neuroscience 310, 206-215. https://doi.org/10.1016/j.neuroscience. 2015.09.042.

Atiyeh, B.S., Costagliola, M., Hayek, S.N., Dibo, S.A., 2007. Effect of silver on burn wound infection control and healing: review of the literature. Burns 33, 139-148. https:// doi.org/10.1016/j.burns.2006.06.010.

Bang, S., Hwang, S.W., 2009. Polymodal ligand sensitivity of TRPA1 and its modes of interactions. J. Gen. Physiol. 133, 257-262. https://doi.org/10.1085/jgp. 200810138.

Bannister, J.V., Calabrese, L., 1987. Assays for superoxide dismutase. In: Methods of Biochemical Analysis. John Wiley \& Sons, Inc., pp. 279-312.

Baraldi, P.G., Preti, D., Materazzi, S., Geppetti, P., 2010. Transient receptor potential Ankyrin 1 (TRPA1) channel as emerging target for novel analgesics and anti-inflammatory agents. J. Med. Chem. 53, 5085-5107. https://doi.org/10.1021/ jm100062h.

Barrot, M., 2012. Tests and models of nociception and pain in rodents. Neuroscience 211 39-50. https://doi.org/10.1016/j.neuroscience.2011.12.041.

Bhatia, N., Kaur, G., Soni, V., Kataria, J., Dhawan, R.K., 2016. Evaluation of the wound healing potential of isoquercetin-based cream on scald burn injury in rats. Burn Trauma 4, 7. https://doi.org/10.1186/s41038-016-0032-1.

Bishop, T., Hewson, D.W., Yip, P.K., Fahey, M.S., Dawbarn, D., Young, A.R., McMahon, S.B., 2007. Characterisation of ultraviolet-B-induced inflammation as a model of hyperalgesia in the rat. Pain 131, 70-82. https://doi.org/10.1016/j.pain.2006.12. 014.

Bradford, M.M., 1976. A rapid and sensitive method for the quantitation of microgram quantities of protein utilizing the principle of protein-dye binding. Anal. Biochem. 72, 248-254. https://doi.org/10.1016/0003-2697(76)90527-3.

Burgess, G., Williams, D., 2010. The discovery and development of analgesics: new mechanisms, new modalities. J. Clin. Invest. 120, 3753-3759. https://doi.org/10.1172/ JCI43195.

Chang, Y.-W., Waxman, S.G., 2010. Minocycline attenuates mechanical allodynia and central sensitization following peripheral second-degree burn injury. J. Pain 11, 1146-1154. https://doi.org/10.1016/j.jpain.2010.02.010.

Chaplan, S.R., Bach, F.W., Pogrel, J.W., Chung, J.M., Yaksh, T.L., 1994. Quantitative assessment of tactile allodynia in the rat paw. J. Neurosci. Methods 53, 55-63. https://doi.org/10.1016/0165-0270(94)90144-9.

Chibli, L.A., Rodrigues, K.C.M., Gasparetto, C.M., Pinto, N.C.C., Fabri, R.L., Scio, E, Alves, M.S., Del-Vechio-Vieira, G., Sousa, O.V., 2014. Anti-inflammatory effects of Bryophyllum pinnatum (Lam.) Oken ethanol extract in acute and chronic cutaneous inflammation. J. Ethnopharmacol. 154, 330-338. https://doi.org/10.1016/j.jep. 2014.03.035.

Cuttle, L., Pearn, J., McMillan, J.R., Kimble, R.M., 2009. A review of first aid treatments for burn injuries. Burns 35, 768-775. https://doi.org/10.1016/j.burns.2008.10.011.

da Costa, D.S.M., Meotti, F.C., Andrade, E.L., Leal, P.C., Motta, E.M., Calixto, J.B., 2010 The involvement of the transient receptor potential A1 (TRPA1) in the maintenance of mechanical and cold hyperalgesia in persistent inflammation. Pain 148, 431-437. https://doi.org/10.1016/j.pain.2009.12.002.

de Oliveira, S., Rosowski, E.E., Huttenlocher, A., 2016. Neutrophil migration in infection and wound repair: going forward in reverse. Nat. Rev. Immunol. 16, 378-391. https://doi.org/10.1038/nri.2016.49.

Dixon, W.J., 1980. Efficient analysis of experimental observations. Annu. Rev. Pharmacol. Toxicol. 20, 441-462. https://doi.org/10.1146/annurev.pa.20.040180.002301.

Edgar, D.W., Fish, J.S., Gomez, M., Wood, F.M., 2011. Local and systemic treatments for acute edema after burn injury: a systematic review of the literature. J. Burn Care Res. 32, 334-347. https://doi.org/10.1097/BCR.0b013e31820ab019.

Eid, S.R., Crown, E.D., Moore, E.L., Liang, H.A., Choong, K.-C., Dima, S., Henze, D.A., Kane, S.A., Urban, M.O., 2008. HC-030031, a TRPA1 selective antagonist, attenuates inflammatory- and neuropathy-induced mechanical hypersensitivity. Mol. Pain 4, 1744-1748. https://doi.org/10.1186/1744-8069-4-48.

Evers, L.H., Bhavsar, D., Mailänder, P., 2010. The biology of burn injury. Exp. Dermatol. 19, 777-783. https://doi.org/10.1111/j.1600-0625.2010.01105.x.

Fowler, M., Clifford, J.L., Garza, T.H., Slater, T.M., Arizpe, H.M., Novak, J., Petz, L.N., Loyd, D.R., 2014. A rat model of full-thickness thermal injury characterized by thermal hyperalgesia, mechanical allodynia, pronociceptive peptide release and tramadol analgesia. Burns 40, 759-771. https://doi.org/10.1016/j.burns.2013.10. 011. 
Fullerton, J.N., Gilroy, D.W., 2016. Resolution of inflammation: a new therapeutic frontier. Nat. Rev. Drug Discov. 15, 551-567. https://doi.org/10.1038/nrd.2016.39. Gamst-Jensen, H., Vedel, P.N., Lindberg-Larsen, V.O., Egerod, I., 2014. Acute pain management in burn patients: appraisal and thematic analysis of four clinical guidelines. Burns 40, 1463-1469. https://doi.org/10.1016/j.burns.2014.08.020.

Gao, Y., Xu, C., Yu, K., Li, G., Wan, F., Liu, S., Lin, J., Liu, H., Zhang, J., Li, X., Liang, S., 2010. Effect of tetramethylpyrazine on DRG neuron P2X3 receptor involved in transmitting pain after burn. Burns 36, 127-134. https://doi.org/10.1016/j.burns. 2009.04.032.

Geppetti, P., Nassini, R., Materazzi, S., Benemei, S., 2008. The concept of neurogenic inflammation. BJU Int. 101, 2-6. https://doi.org/10.1111/j.1464-410X.2008. 07493.x.

Gherardini, G., Curinga, G., Colella, G., Freda, N., Rauso, R., 2009. Calcitonin gene-related peptide and termal injury: review of literature. Eplasty 9, e30.

Gouin, O., L'Herondelle, K., Lebonvallet, N., Le Gall-Ianotto, C., Sakka, M., Buhé, V., PléeGautier, E., Carré, J.-L., Lefeuvre, L., Misery, L., Le Garrec, R., 2017. TRPV1 and TRPA1 in cutaneous neurogenic and chronic inflammation: pro-inflammatory response induced by their activation and their sensitization. Protein Cell. 8, 644-661. https://doi.org/10.1007/s13238-017-0395-5.

Green, D.P., Ruparel, S., Gao, X., Ruparel, N., Patil, M., Akopian, A., Hargreaves, K.M. 2016. Central activation of TRPV1 and TRPA1 by novel endogenous agonists contributes to mechanical and thermal allodynia after burn injury. Mol. Pain 12, 174480691666172. https://doi.org/10.1177/1744806916661725.

Griggs, R.B., Laird, D.E., Donahue, R.R., Fu, W., Taylor, B.K., 2017. Methylglyoxal requires AC1 and TRPA1 to produce pain and spinal neuron activation. Front. Neurosci. 11. https://doi.org/10.3389/fnins.2017.00679.

Hatano, N., Itoh, Y., Suzuki, H., Muraki, Y., Hayashi, H., Onozaki, K., Wood, I.C., Beech, D.J., Muraki, K., 2012. Hypoxia-inducible factor-1 $\alpha$ (HIF1 $\alpha$ ) switches on transient receptor potential ankyrin repeat 1 (TRPA1) gene expression via a hypoxia response element-like motif to modulate cytokine release. J. Biol. Chem. 287, 31962-31972. https://doi.org/10.1074/jbc.M112.361139.

Hinman, R.S., Heywood, S.E., Day, A.R., 2007. Aquatic physical therapy for hip and knee osteoarthritis: results of a single-blind randomized controlled trial. Phys. Ther. 87, 32-43. https://doi.org/10.2522/ptj.20060006.

Horváth, Á., Tékus, V., Boros, M., Pozsgai, G., Botz, B., Borbély, É., Szolcsányi, J., Pintér, E., Helyes, Z., 2016. Transient receptor potential ankyrin 1 (TRPA1) receptor is involved in chronic arthritis: in vivo study using TRPA1-deficient mice. Arthritis Res. Ther. 18, 6. https://doi.org/10.1186/s13075-015-0904-y.

Hoşnuter, M., Gürel, A., Babucçu, O., Armutcu, F., Kargi, E., Işikdemir, A., 2004. The effect of CAPE on lipid peroxidation and nitric oxide levels in the plasma of rats following thermal injury. Burns 30,121-125. https://doi.org/10.1016/j.burns.2003. 09.022

Infanger, M., Schmidt, O., Kossmehl, P., Grad, S., Ertel, W., Grimm, D., 2004. Vascular endothelial growth factor serum levels is strongly enhanced after burn injury and correlated with local and general tissue edema. Burns 30, 305-311.

Irimia, P., Palma, J.-A., Fernandez-Torron, R., Martinez-Vila, E., 2011. Refractory migraine in a headache clinic population. BMC Neurol. 11, 94. https://doi.org/10. 1186/1471-2377-11-94.

Jaggi, A.S., Singh, N., 2011. Exploring the potential of telmisartan in chronic constriction injury-induced neuropathic pain in rats. Eur. J. Pharmacol. 667, 215-221. https:// doi.org/10.1016/j.ejphar.2011.06.017.

James, D.L., Jowza, M., 2017. Principles of burn pain management. Clin. Plast. Surg. 44, 737-747. https://doi.org/10.1016/j.cps.2017.05.005.

Jeschke, M.G., Gauglitz, G.G., Song, J., Kulp, G.A., Finnerty, C.C., Cox, R.A., Barral, J.M., Herndon, D.N., Boehning, D., 2009. Calcium and ER stress mediate hepatic apoptosis after burn injury. J. Cell. Mol. Med. 13, 1857-1865. https://doi.org/10.1111/j.15824934.2009.00644.x.

Keeble, J.E., Bodkin, J.V., Liang, L., Wodarski, R., Davies, M., Fernandes, E.S., Coelho, C. de F., Russell, F., Graepel, R., Muscara, M.N., Malcangio, M., Brain, S.D., 2009. Hydrogen peroxide is a novel mediator of inflammatory hyperalgesia, acting via transient receptor potential vanilloid 1-dependent and independent mechanisms. Pain 141, 135-142. https://doi.org/10.1016/j. pain.2008.10.025.

Kittaka, H., Tominaga, M., 2017. The molecular and cellular mechanisms of itch and the involvement of TRP channels in the peripheral sensory nervous system and skin. Allergol. Int. 66, 22-30.

Klafke, J.Z., da Silva, M.A., Rossato, M.F., de Prá, S.D.T., Rigo, F.K., Walker, C.I.B., Bochi, G.V., Moresco, R.N., Ferreira, J., Trevisan, G., 2016. Acute and chronic nociceptive phases observed in a rat hind paw ischemia/reperfusion model depend on different mechanisms. Pflugers Arch. - Eur. J. Physiol. 468, 229-241. https://doi.org/10. 1007/s00424-015-1746-9.

Kondo, T., Sakurai, J., Miwa, H., Noguchi, K., 2013. Activation of p38 MAPK through transient receptor potential A1 in a rat model of gastric distension-induced viscera pain. Neuroreport 24, 68-72. https://doi.org/10.1097/WNR.0b013e32835c7df2.

Labuz, D., Machelska, H., 2013. Stronger antinociceptive efficacy of opioids at the injured nerve trunk than at its peripheral terminals in neuropathic pain. J. Pharmacol. Exp. Ther. 346, 535-544. https://doi.org/10.1124/jpet.113.205344.

Laycock, H., Valente, J., Bantel, C., Nagy, I., 2013. Peripheral mechanisms of burn injuryassociated pain. Eur. J. Pharmacol. 716, 169-178. https://doi.org/10.1016/j.ejphar. 2013.01.071.

Lee, H., Kaneki, M., Andreas, J., Tompkins, R.G., Martyn, J.A.J., 2011. Novel mitochondria-targeted antioxidant peptide ameliorates burn-induced apoptosis and endoplasmic reticulum stress in the skeletal muscle of mice. Shock 36, 580-585. https://doi.org/10.1097/SHK.0b013e3182366872.

Lee, E.G., Mickle-Kawar, B.M., Gallucci, R.M., 2013. IL-6 deficiency exacerbates skin inflammation in a murine model of irritant dermatitis. J. Immunotoxicol. 10, 192-200. https://doi.org/10.3109/1547691X.2012.707700.
Lee, K.I., Lee, H.T., Lin, H.C., Tsay, H.J., Tsai, F.C., Shyue, S.K., Lee, T.S., 2016. Role of transient receptor potential ankyrin 1 channels in Alzheimer's disease. J. Neuroinflammation 13, 92. https://doi.org/10.1186/s12974-016-0557-z.

Levine, J.D., Alessandri-Haber, N., 2007. TRP channels: targets for the relief of pain. Biochim. Biophys. Acta Mol. basis Dis. 1772, 989-1003. https://doi.org/10.1016/j. bbadis.2007.01.008.

Lin, A.H., Liu, M.H., Ko, H.K., Perng, D.W., Lee, T.S., Kou, Y.R., 2015. Lung epithelial TRPA1 transduces the extracellular ROS into transcriptional regulation of lung inflammation induced by cigarette smoke: the role of Influxed $\mathrm{Ca}^{2+}$. Mediat. Inflamm. 2015, 148367. https://doi.org/10.1155/2015/148367.

Marx, D.E., Barillo, D.J., 2014. Silver in medicine: the basic science. Burns 40, S9-S18. https://doi.org/10.1016/j.burns.2014.09.010.

McGaraughty, S., Chu, K.L., Perner, R.J., Didomenico, S., Kort, M.E., Kym, P.R., 2010 TRPA1 modulation of spontaneous and mechanically evoked firing of spinal neurons in uninjured, osteoarthritic, and inflamed rats. Mol. Pain 6https://doi.org/10.1186/ 1744-8069-6-14. (1744-8069-6-14)

McGrath, J.C., Lilley, E., 2015. Implementing guidelines on reporting research using animals (ARRIVE etc.): new requirements for publication in BJP. Br. J. Pharmacol. 172, 3189-3193. https://doi.org/10.1111/bph.12955.

McIntyre, M.K., Clifford, J.L., Maani, C.V., Burmeister, D.M., 2016. Progress of clinical practice on the management of burn-associated pain: lessons from animal models. Burns 42, 1161-1172. https://doi.org/10.1016/j.burns.2016.01.023.

Moilanen, L.J., Hämäläinen, M., Lehtimäki, L., Nieminen, R.M., Moilanen, E., 2015. Urate crystal induced inflammation and joint pain are reduced in transient receptor potential Ankyrin 1 deficient mice - potential role for transient receptor potential Ankyrin 1 in gout. PLoS One 10, e0117770. https://doi.org/10.1371/journal.pone. 0117770.

Monstrey, S., Hoeksema, H., Verbelen, J., Pirayesh, A., Blondeel, P., 2008. Assessment of burn depth and burn wound healing potential. Burns 34, 761-769. https://doi.org/ 10.1016/j.burns.2008.01.009.

Monteith, T.S., Goadsby, P.J., 2011. Acute migraine therapy: new drugs and new approaches. Curr. Treat. Options Neurol. 13, 1-14. https://doi.org/10.1007/s11940010-0105-6.

Mori, Y., Takahashi, N., Polat, O.K., Kurokawa, T., Takeda, N., Inohue, M., 2016. Redoxsensitive transient receptor potential channels in oxygen sensing and adaptation. Pflugers Arch. 468, 85-97. https://doi.org/10.1007/s00424-015-1716-2.

Nadworny, P.L., Wang, J., Tredget, E.E., Burrell, R.E., 2008. Anti-inflammatory activity of nanocrystalline silver in a porcine contact dermatitis model. Nanomed. Nanotechnol., Biol. Med. 4, 241-251. https://doi.org/10.1016/j.nano.2008.04.006.

Nakamura, Y., Murakami, A., Ohto, Y., Torikai, K., Tanaka, T., 1998. Suppression of tumor promoter-induced oxidative stress and inflammatory responses in mouse skin by a superoxide generation inhibitor 1'-Acetoxychavicol acetate. Cancer Res. 58, 4832-4839.

Namer, B., Seifert, F., Handwerker, H.O., Maihöfner, C., 2005. TRPA1 and TRPM8 activation in humans: effects of cinnamaldehyde and menthol. Neuroreport 16, 955-959. https://doi.org/10.1097/00001756-200506210-00015.

Nasiri, E., Hosseinimehr, S.J., Zaghi Hosseinzadeh, A., Azadbakht, M., Akbari, J., Azadbakht, M., 2016. The effects of Arnebia euchroma ointment on second-degree burn wounds: a randomized clinical trial. J. Ethnopharmacol. 189, 107-116. https:// doi.org/10.1016/j.jep.2016.05.029.

Nassini, R., Materazzi, S., Benemei, S., Geppetti, P., 2014. The TRPA1 channel in inflammatory and neuropathic pain and migraine. In: Nilius, B., Gudermann, T., Jahn, R., Lill, R., Offermanns, S., Petersen, O.H. (Eds.), Reviews of Physiology, Biochemistry and Pharmacology. Springer International Publishing, Cham, pp. 1-43.

Oliveira, S.M., Silva, C.R., Wentz, A.P., Paim, G.R., Correa, M.S., Bonacorso, H.G. Prudente, A.S., Otuki, M.F., Ferreira, J., 2014. Antinociceptive effect of 3-(4-fluorophenyl)-5-trifluoromethyl-1H-1-tosylpyrazole. A celecoxib structural analog in models of pathological pain. Pharmacol. Biochem. Behav. 124, 396-404. https://doi. org/10.1016/j.pbb.2014.07.005.

Paemeleire, K., Crevits, L., Goadsby, P.J., Kaube, H., 2006. Practical management of medication-overuse headache. Acta Neurol. Belg. 106, 43-51.

Parihar, A., Parihar, M.S., Milner, S., Bhat, S., 2008. Oxidative stress and anti-oxidative mobilization in burn injury. Burns 34, 6-17. https://doi.org/10.1016/j.burns.2007. 04.009.

Petrus, M., Peier, A.M., Bandell, M., Hwang, S.W., Huynh, T., Olney, N., Jegla, T. Patapoutian, A., 2007. A role of TRPA1 in mechanical hyperalgesia is revealed by pharmacological inhibition. Mol. Pain 3https://doi.org/10.1186/1744-8069-3-40. 1744-8069-3-40.

Piana, M., Silva, M.A., Trevisan, G., de Brum, T.F., Silva, C.R., Boligon, A.A., Oliveira, S.M., Zadra, M., Hoffmeister, C., Rossato, M.F., Tonello, R., Laporta, L.V., de Freitas, R.B., Belke, B.V., Jesus, R. da S., Ferreira, J., Athayde, M.L., 2013. Antiinflammatory effects of Viola tricolor gel in a model of sunburn in rats and the gel stability study. J. Ethnopharmacol. 150, 458-465. https://doi.org/10.1016/j.jep.2013.08.040.

Piccolo, N., Serra, M., Leonardi, D., Lima Jr., E., Novaes, F., Correa, M., Cunha, L., Amaral, C., Prestes, M., Cunha, S., Piccolo, M., 2008. Projeto Diretrizes Queimaduras: Diagnóstico e Tratamento Inicial, 1st ed. Sociedade Brasileira de Cirurgia Plástica, Sao Paulo, Brazil.

Pinheiro, F.D.V., Villarinho, J.G., Silva, C.R., Oliveira, S.M., Pinheiro, K.D.V., Petri, D., Rossato, M.F., Guerra, G.P., Trevisan, G., Antonello Rubin, M., Geppetti, P., Ferreira, J., André, E., 2015. The involvement of the TRPA1 receptor in a mouse model of sympathetically maintained neuropathic pain. Eur. J. Pharmacol. 747, 105-113. https://doi.org/10.1016/j.ejphar.2014.11.039.

Raisinghani, M., Zhong, L., Jeffry, J.A., Bishnoi, M., Pabbidi, R.M., Pimentel, F., Cao, D. S., Steven Evans, M., Premkumar, L.S., 2011. Activation characteristics of transient receptor potential ankyrin 1 and its role in nociception. Am. J. Physiol. Physiol. 301, C587-C600. https://doi.org/10.1152/ajpcell.00465.2010. 
Richardson, P., Mustard, L., 2009. The management of pain in the burns unit. Burns 35, 921-936. https://doi.org/10.1016/j.burns.2009.03.003.

Rock, C.L., Dechert, R.E., Khilnani, R., Parker, R.S., Rodriguez, J.L., 1997. Carotenoids and antioxidant vitamins in patients after burn injury. J. Burn Care Rehabil. 18, 268-278. https://doi.org/10.1097/00004630-199705000-00018.

Rowan, M.P., Cancio, L.C., Elster, E.A., Burmeister, D.M., Rose, L.F., Natesan, S., Chan, R.K., Christy, R.J., Chung, K.K., 2015. Burn wound healing and treatment: review and advancements. Crit. Care 19, 243. https://doi.org/10.1186/s13054-015-0961-2.

Sawada, Y., Hosokawa, H., Matsumura, K., Kobayashi, S., 2008. Activation of transient receptor potential ankyrin 1 by hydrogen peroxide. Eur. J. Neurosci. 27, 1131-1142. https://doi.org/10.1111/j.1460-9568.2008.06093.x.

Serrano, C., Boloix-Tortosa, R., Gómez-Cía, T., Acha, B., 2015. Features identification for automatic burn classification. Burns 41, 1883-1890. https://doi.org/10.1016/j. burns.2015.05.011.

Shahzad, M.N., Ahmed, N., 2013. Effectiveness of Aloe Vera gel compared with 1\% silver sulphadiazine cream as burn wound dressing in second degree burns. J. Pak. Med. Assoc. 63, 225-230.

Silva, M.A., Trevisan, G., Klafke, J.Z., Rossato, M.F., Walker, C.I.B., Oliveira, S.M., Silva, C.R., Boligon, A.A., Flores, F.C., Silva, C.D.B., Athayde, M.L., Ferreira, J., 2013. Antinociceptive and anti-inflammatory effects of Aloe saponaria Haw on thermal injury in rats. J. Ethnopharmacol. 146, 393-401. https://doi.org/10.1016/j.jep. 2012.12.055.

Silva, M.A., Trevisan, G., Hoffmeister, C., Rossato, M.F., Boligon, A.A., Walker, C.I.B., Klafke, J.Z., Oliveira, S.M., Silva, C.R., Athayde, M.L., Ferreira, J., 2014. Anti-inflammatory and antioxidant effects of Aloe saponaria Haw in a model of UVB-induced paw sunburn in rats. J. Photochem. Photobiol. B Biol. 133, 47-54. https://doi.org/ 10.1016/j.jphotobiol.2014.02.019.

Silveira, P.C.L., Ferreira, K.B., da Rocha, F.R., Pieri, B.L.S., Pedroso, G.S., De Souza, C.T., Nesi, R.T., Pinho, R.A., 2016. Effect of low-power laser (LPL) and light-emitting diode (LED) on inflammatory response in burn wound healing. Inflammation. https://doi. org/10.1007/s10753-016-0371-x.

Siney, L., Brain, S.D., 1996. Involvment of sensory neuropeptides in the development of plasma extravasation in rat dorsal skin following thermal injury. Br. J. Pharmacol. 117, 1065-1070.

Singer, A.J., Dagum, A.B., 2008. Current management of acute cutaneous wounds. N. Engl. J. Med. 359, 1037-1046. https://doi.org/10.1056/NEJMra0707253.

Sommer, K., Sander, A.L., Albig, M., Weber, R., Henrich, D., Frank, J., et al., 2013. Delayed wound repair in sepsis is associated with reduced local pro-inflammatory cytokine expression. PLoS One 8. https://doi.org/10.1371/journal.pone.0073992.

Song, H.Y., Lee, J.A., Ju, S.M., Yoo, K., Won, M.H., Kwon, H., Eum, W.S., Jang, S.H., Choi, S.Y., Park, J., 2008. Topical transduction of superoxide dismutase mediated by HIV-1 Tat protein transduction domain ameliorates 12-O-tetradecanoylphorbol-13-acetate (TPA)-induced inflammation in mice. Biochem. Pharmacol. 75, 1348-1357. https:// doi.org/10.1016/j.bcp.2007.11.015.

Sousa-Valente, J., Andreou, A.P., Urban, L., Nagy, I., 2014. Transient receptor potential ion channels in primary sensory neurons as targets for novel analgesics. Br. J. Pharmacol. 171, 2508-2527. https://doi.org/10.1111/bph.12532.

Souza, H.R., de Azevedo, L.R., Possebon, L., Costa, S. de S., Iyomasa-Pilon, M.M., Oliani, S.M., Girol, A.P., 2017. Heterogeneity of mast cells and expression of Annexin A1 protein in a second degree burn model with silver sulfadiazine treatment. PLoS One 12, e0173417. https://doi.org/10.1371/journal.pone.0173417.

Stovner, L.J., Tronvik, E., Hagen, K., 2009. New drugs for migraine. J. Headache Pain 10, 395-406. https://doi.org/10.1007/s10194-009-0156-9.

Summer, G.J., Puntillo, K.A., Miaskowski, C., Green, P.G., Levine, J.D., 2007. Burn injury pain: the continuing challenge. J. Pain 8, 533-548. https://doi.org/10.1016/j.jpain. 2007.02.426.

Takahashi, K., Sato, J., Mizumura, K., 2003. Responses of C-fiber low threshold mechanoreceptors and nociceptors to cold were facilitated in rats persistently inflamed and hypersensitive to cold. Neurosci. Res. 47, 409-419. https://doi.org/10.1016/j. neures.2003.08.003.

Tanaka, H., Lund, T., Wiig, H., Reed, R.K., Yukioka, T., Matsuda, H., Shimazaki, S., 1999. High dose vitamin $\mathrm{C}$ counteracts the negative interstitial fluid hydrostatic pressure and early edema generation in thermally injured rats. Burns 25, 569-574. https:// doi.org/10.1016/S0305-4179(99)00073-X.

Taylor-Clark, T.E., Undem, B.J., 2010. Ozone activates airway nerves via the selective stimulation of TRPA1 ion channels. J. Physiol. 588, 423-433. https://doi.org/10. 1113/jphysiol.2009.183301.

Treede, R.-D., Rief, W., Barke, A., Aziz, Q., Bennett, M.I., Benoliel, R., Cohen, M., Evers, S., Finnerup, N.B., First, M.B., Giamberardino, M.A., Kaasa, S., Kosek, E., Lavand'homme, P., Nicholas, M., Perrot, S., Scholz, J., Schug, S., Smith, B.H., Svensson, P., Vlaeyen, J.W.S., Wang, S.-J., 2015. A classification of chronic pain for ICD-11. Pain 156, 1. https://doi.org/10.1097/j.pain.0000000000000160.

Trevisan, G., Hoffmeister, C., Rossato, M.F., Oliveira, S.M., Silva, M.A., Ineu, R.P., Guerra, G.P., Materazzi, S., Fusi, C., Nassini, R., Geppetti, P., Ferreira, J., 2013. Transient receptor potential Ankyrin 1 receptor stimulation by hydrogen peroxide is critical to trigger pain during monosodium urate-induced inflammation in rodents. Arthritis Rheum. 65, 2984-2995. https://doi.org/10.1002/art.38112.

Trevisan, G., Hoffmeister, C., Rossato, M.F., Oliveira, S.M., Silva, M.A., Silva, C.R., Fusi, C., Tonello, R., Minocci, D., Guerra, G.P., Materazzi, S., Nassini, R., Geppetti, P., Ferreira, J., 2014. TRPA1 receptor stimulation by hydrogen peroxide is critical to trigger hyperalgesia and inflammation in a model of acute gout. Free Radic. Biol. Med. 72, 200-209. https://doi.org/10.1016/j.freeradbiomed.2014.04.021.

Trevisan, G., Benemei, S., Materazzi, S., De Logu, F., De Siena, G., Fusi, C., Fortes, M.F., Coppi, E., Marone, I.M., Ferreira, J., Geppetti, P., Nassini, R., 2016. TRPA1 mediates trigeminal neuropathic pain in mice downstream of monocytes/macrophages and oxidative stress. Brain 139, 1361-1377. https://doi.org/10.1093/brain/aww038.

Trevisani, M., Siemens, J., Materazzi, S., Bautista, D.M., Nassini, R., Campi, B., Imamachi, N., Andrè, E., Patacchini, R., Cottrell, G.S., Gatti, R., Basbaum, A.I., Bunnett, N.W., Julius, D., Geppetti, P., 2007. 4-Hydroxynonenal, an endogenous aldehyde, causes pain and neurogenic inflammation through activation of the irritant receptor TRPA1. Proc. Natl. Acad. Sci. U. S. A. 104, 13519-13524. https://doi.org/10.1073/pnas. 0705923104.

Tsagareli, M.G., Tsiklauri, N., Zanotto, K.L., Carstens, M.I., Klein, A.H., Sawyer, C.M., Gurtskaia, G., Abzianidze, E., Carstens, E., 2010. Behavioral evidence of thermal hyperalgesia and mechanical allodynia induced by intradermal cinnamaldehyde in rats. Neurosci. Lett. 473, 233-236. https://doi.org/10.1016/j.neulet.2010.02.056.

Ueda, M., Iwasaki, H., Wang, S., Murata, E., Poon, K.Y.T., Mao, J., Martyn, J.A.J., 2014. Cannabinoid receptor type 1 antagonist, AM251, attenuates mechanical allodynia and thermal hyperalgesia after burn injury. Anesthesiology 121, 1311-1319. https:// doi.org/10.1097/ALN.0000000000000422.

Vandewauw, I., De Clercq, K., Mulier, M., Held, K., Pinto, S., Van Ranst, N., Segal, A., Voet, T., Vennekens, R., Zimmermann, K., Vriens, J., Voets, T., 2018. A TRP channel trio mediates acute noxious heat sensing. Nature 555, 662-666. https://doi.org/10. 1038/nature26137.

Viana, F., 2016. TRPA1 channels: molecular sentinels of cellular stress and tissue damage. J. Physiol. 594, 4151-4169. https://doi.org/10.1113/JP270935.

Volpi, G., Facchinetti, F., Moretto, N., Civelli, M., Patacchini, R., 2011. Cigarette smoke and $\alpha, \beta$-unsaturated aldehydes elicit VEGF release through the p38 MAPK pathway in human airway smooth muscle cells and lung fibroblasts. Br. J. Pharmacol. 163, 649-661. https://doi.org/10.1111/j.1476-5381.2011.01253.x.

Walls, R.M., Hockberger, R., Gausche-Hill, M., 2017. Rosen's Emergency Medicine: Concepts and Clinical Practice, 9th ed. Elsevier, Amsterdam.

Wasiak, J., Cleland, H., Campbell, F., Spinks, A., 2013. Dressings for superficial and partial thickness burns. Cochrane Database Syst. Rev. https://doi.org/10.1002/ 14651858.CD002106.pub4.

Weissman-Fogel, I., Dashkovsky, A., Rogowski, Z., Yarnitsky, D., 2008. Vagal damage enhances polyneuropathy pain: additive effect of two algogenic mechanisms. Pain 138, 153-162. https://doi.org/10.1016/j.pain.2007.11.017.

Xie, B., Xiao, S., Zhu, S., Xia, Z., 2012. Evaluation of long term health-related quality of life in extensive burns: a 12-year experience in a burn center. Burns 38, 348-355. https://doi.org/10.1016/j.burns.2011.09.003.

Zimmermann, M., 1983. Ethical guidelines for investigations of experimental pain in conscious animals. Pain 16, 109-110. https://doi.org/10.1016/0304-3959(83) 90201-4. 